\title{
Seismic performance evaluation and design of steel structures equipped with dual-pipe dampers
}

\author{
Saeed Mahjoubi ${ }^{*}, 1$, Shervin Maleki ${ }^{2}$ \\ ${ }^{1}$ Department of Civil Engineering, Science and Research Branch, Islamic Azad University, Tehran, Iran \\ ${ }^{2}$ Department of Civil Engineering, Sharif University of Technology, Azadi Ave., Tehran, Iran
}

\begin{abstract}
Dual-pipe damper (DPD) is a metallic yielding device for passive control of structures, introduced recently by the authors. The objective of the current study is to provide guidelines for implementing DPDs in actual steel buildings, evaluate and compare their performance against other metallic dampers. In this study, a representative load-displacement model for DPDs is proposed for the first time, and assessed based on previous experimental cyclic tests. Guidelines for the design of DPD devices are also presented. Three steel moment resisting frames of 5, 10 and 20 stories are designed and then equipped with DPDs of various properties. The responses of the frames to seven earthquake excitations are investigated using dynamic nonlinear timehistory analyses. Performance of the DPD devices is then evaluated through various response parameters including the normalized energy ratios. The results prove the effectiveness of the DPD devices in dissipating a considerable portion of the input seismic energy and significantly reducing the non-structural and structural damage. The responses of a 10-story frame equipped with DPDs are compared to those of the frame with TADAS devices. The results show that the structure equipped with DPD, with its unique secondary hardening portion in forcedisplacement, results lower structural and non-structural damage compared to TADAS.
\end{abstract}

Keywords: Dual-pipe damper; Seismic performance; Passive control; Structural control; Nonlinear response; Metallic damper.

\footnotetext{
* Corresponding author. E-mail address: mahjoubi@ srbiau.ac.ir
} 


\section{Introduction}

The traditional concept of designing building frames for seismic loads is based on the plastification of the main elements of a structure such as beams, columns, braces, etc. As a result, the energy dissipation in frame members can lead to undesirable structural damage to the load-carrying elements. Moreover, most structural elements exhibit strength degradation and low damping after the very first cycles of an earthquake excitation. To avoid these deficiencies, the concept of structural control was proposed and developed by several researchers during the last four decades [1,2]. Yielding of metals was first suggested by Kelly et al. [3] in the early 1970s as a mechanism for structural control. It was soon proved to be one of the most economical and effective mechanisms of passive control. Several yielding metallic dampers have been developed for structural application during the last two decades; among which, the most popular devices have been the X-shaped ADAS device [4], triangular TADAS device [5], honeycomb damper [6], shear-panel damper [7] and buckling-restrained braces (BRB) [8].

Recently, pipe damper was introduced by Maleki and Bagheri $[9,10]$ as a simple passive device, using a steel pipe loaded in shear. Despite its excellent ductility, the device demonstrated low stiffness and strength compared to some other passive dissipative devices. To enhance the effectiveness and performance of the pipe damper, Maleki and Mahjoubi [11] introduced a dual pipe system connected with a special welding scheme. This new passive device was called the dual-pipe damper or DPD. The device consists of two horizontal pipes in contact, welded to each other and to top and bottom supporting plates at certain locations (See Fig. 1). Later in 2014, an in-filled version of DPD, called the infilled pipe damper (IPD), was proposed by the authors [12] to enhance the performance even further.

Experimental quasi-static cyclic tests were performed on four DPD specimens [11], all displayed high ductility and stable hystereses up to relatively large displacements. Fig. 2 displays the deformed shape of a DPD specimen made with $110 \mathrm{~mm}$ diameter, $4.1 \mathrm{~mm}$ thick pipes, after failure. DPD devices dissipate seismic energy through plastic deformation of steel 
pipes, mainly in flexural form. At large deformations, a stiffening behavior was observed in the hystereses of the DPD specimens [11]. The stiffening behavior is attributed to a tensile-flexural action formed in the central part of the DPD in relatively large deformations (see Fig. 2). This causes gradual increase of plastic stiffness and strength to a much higher value. This behavior can prevent large drifts and $P-\Delta$ moments in structures subjected to severe earthquakes.

Advantages of the DPD over many available metallic dampers, such as its light weight, low cost, simple manufacturing, large force to weight ratio, large dissipated energy to weight ratio and large deformation capacity (30\% to $36 \%$ its height) makes it an economical and effective solution for passive energy dissipation in both new structures and structures to be retrofitted [11].

Several researches have been performed in the fields of response evaluation, optimization and design of structures with hysteretic dampers of different types [13-24]. Xia and Hanson [13] carried out a parametric study on two 10-story building frames equipped with ADAS devices to find out their performance and response to seismic loading. They identified the yield displacement, strain-hardening ratio, ratio of the device stiffness to the bracing member stiffness and ratio of the device stiffness to the story stiffness as the most important parameters, distinguishing the performance of yielding dampers in frames.

Curadelli and Riera [14] considered 6-story concrete and 9-story steel moment resisting frame structures with metallic dampers. They calculated the fragility curves of the structures with and without passive devices and concluded that the probability of failure of the structures may be decreased to $1 / 5$ of the initial value by introducing external metallic dampers in the cases studied.

Kim and Choi [17] investigated energy dissipation capacity and nonlinear dynamic response of two five- and ten-story steel structures equipped with buckling-restrained braces and proposed a design procedure to meet a given target displacement. Oviedo et al. [24] studied the earthquake response of a ten-story reinforced concrete building structure with hysteretic 
dampers. The three parameters considered were damper to frame strength and stiffness ratios and yield drift ratio; however, only two of the parameters were independent. They concluded that structures with low yield story drift ratio demonstrate the largest reduction in the inelastic demand and permanent damage to the main frame.

The objective of the current study is to guide designers in implementing DPDs in actual steel buildings and to evaluate the DPD performance in reducing the seismic responses of steel frames. Considering the second hardening branch observed in force-displacement of DPDs, the other goal of this study is to evaluate the effect of this specific property of DPDs on preventing damage to the building frames. First, a simple load-displacement model for DPDs is suggested to be used in nonlinear analyses, for the first time. Design guidelines for DPDs are also proposed. The responses of three steel structures equipped with DPDs of various yield strengths are obtained using nonlinear dynamic time-history analyses and compared to those of bare frames. Energy dissipation of dampers and frames subjected to the earthquake motions are evaluated and discussed. The results show that DPD devices can prevent destructive damage to main frame elements by dissipating almost all the hysteretic energy which would be imposed to a building in an earthquake.

\section{Simplified force-displacement model of DPDs}

The following relationships are recommended for mechanical properties of DPDs, based on tests and numerical studies [11]. In these relationships: $100 \leq \mathrm{D} \leq 350 \mathrm{~mm}$ and $20 \leq \mathrm{D} / \mathrm{t} \leq 35$. The material considered is ASTM A-36 steel.

$$
\begin{aligned}
& \Delta_{y}=0.0001(4.75 D-8.2)(D / t) \\
& K_{0}=3156 L(D / t)^{-3.14} \\
& \mu=333(D / t)^{-0.8}
\end{aligned}
$$




$$
E_{D}=0.015 L \cdot t^{1.77}
$$

in which $\Delta_{y}, K_{0}, \mu$ and $E_{D}$ denote DPD yield displacement (mm), DPD elastic stiffness $(\mathrm{kN} / \mathrm{mm})$, DPD ultimate ductility and total energy dissipated by DPD (kJ), respectively. $D, t$ and $L$ are the pipes diameter, thickness and length in $\mathrm{mm}$. Note, however, the total dissipated energy and ductility of a passive damper depend also on material properties and loading history. The values calculated by Eqs. (3) and (4) are approximate in nature and may be used as a reference value.

Having the parameters $K_{0}, \Delta_{y}$ and $\mu$, one can easily calculate the parameters $P_{y}$ (yield force) and $\Delta_{u}$ (ultimate displacement) by basic mechanics.

Herein, a trilinear characteristic model is proposed to represent the DPDs inelastic behavior for further analytical investigations (see Fig. 3). The model is simple, yet able to consider the strain hardening and the second hardening branch of DPDs. The elastic stiffness $\left(K_{e}\right)$ of the trilinear model can be calculated from Eq. (2). The equivalent yield displacement in the trilinear model is assumed 1.5 times of that calculated by Eq. (1), on the basis of the experimental and FE study results [11].

The nonlinear stiffness $\left(K_{p}\right)$ and large deformation stiffness $\left(K_{l}\right)$ values are suggested to be $6 \%$ and $25 \%$ of the DPD elastic stiffness, respectively, based on the experimental and analytical study [11]. It should be noted that the hysteretic energy is nearly independent of the nonlinear to linear stiffness ratio $\left(K_{p} / K_{e}\right)[13,15]$; therefore, the proposed $K_{p}$ and $K_{l}$ values may be used in the absence of more accurate data.

The deformation at which the stiffness changes to large deformation stiffness $\left(\Delta_{p}\right)$ should be considered as 0.2 times the pipe diameter, based on the results of experimental and analytical studies [11]. The proposed trilinear load-displacement of DPD can be used for monotonic loading as well as the backbone for cyclic loading.

Fig. 4 shows the simplified trilinear load-displacement for M1L100 (DPD with $D=140 \mathrm{~mm}$, $t=5.1 \mathrm{~mm}$ and $L=200$ ) and M3L50 (DPD with $D=110 \mathrm{~mm}, t=4.1 \mathrm{~mm}$ and $L=100$ ) specimens together with hysteresis loops obtained from cyclic tests of the specimens [11]. As it can be 
concluded from Fig. 4, the trilinear load-displacement model, superimposed on the curves,

works well as the backbone of the specimens hysteresis.

\section{Behavior of structures with hysteretic dampers}

The fundamental energy relationship of a structure during an earthquake can be written as [25]

$E_{I}=E_{K}+E_{S}+E_{H}+E_{\xi}$

in which $E_{I}, E_{K}, E_{S}, E_{H}$ and $E_{\xi}$ are the absolute energy input from the earthquake motion, absolute kinetic energy, recoverable elastic strain energy, hysteretic irrecoverable energy and viscous energy, respectively.

The absolute energy input, $E_{I}$, denotes the absolute work done by the base shear force on the structure during an earthquake. The input energy turns into a combination of kinetic and potential (strain) energies, either absorbed by the structural elements or dissipated through heat by the inherent damping of the structure and supplemental devices [26]. Hysteretic dampers, as supplemental devices, improve the structural performance by absorbing, as much as possible, the $E_{H}$ portion of the input energy through inelastic action, thereby reducing the burden on the building frame. The goal of incorporating added damping devices into a structure is to minimize the main frame damage by decreasing the frame inelastic absorbed energy.

Neglecting the overall bending of a structure, the entire system of frame and hysteretic dampers may be assumed as two parallel springs; in other words, the dampers sustain the same deformation as the frame does at each story. Consequently, the stiffness and strength of the entire system can be obtained through summation of the two spring properties. Fig. 5 demonstrates the idealized force-displacement behavior of a structural system containing DPD devices.

Among four possible installation schemes of DPDs in structures, introduced in [11], the DPDs are considered to be installed on top of inverted-V braces, in this study (see Fig. 1.b). The 
effective horizontal stiffness of the DPD device and the inverted-V brace as a whole, $K_{\text {eff }}$, can be

calculated based on the formula for stiffness of two springs in series. The relationship is

$$
\begin{aligned}
& \frac{1}{K_{\text {eff }}}=\frac{1}{K_{d}}+\frac{1}{K_{b}} \rightarrow K_{e f f}=\frac{K_{d} \cdot K_{b}}{K_{d}+K_{b}} \\
& K_{e f f}=\frac{K_{d}}{1+\frac{1}{\left(\frac{K_{b}}{K_{d}}\right)}}
\end{aligned}
$$

where $K_{b}$ and $K_{d}$ are the inverted-V brace stiffness and the DPD device stiffness, respectively. According to Eq. (7), the effective stiffness is always less than the DPD stiffness. The $K_{b} / K_{d}$ parameter plays a major role in the damped systems behavior. By increasing the $K_{b} / K_{d}$ parameter, $K_{\text {eff }}$ approaches $K_{d}$; however, it is neither practical nor economical to increase the parameter excessively. Xia and Hanson [13] suggested $K_{b} / K_{d}$ values greater than 2 , considering both damper system performance and cost of bracing members. In this study, we use $K_{b} / K_{d}$ equal to 2.5. The minimum horizontal strength of the inverted-V braces in buckling or yielding is also checked to be at least 1.2 times of the force generated in braces by the strength of DPDs, to ensure that the braces remain elastic.

\section{Modeling and analyses}

\subsection{Bare frame structures}

Three buildings of five, ten and twenty stories representing short, medium and long period structures are considered for the parametric study. Building plans are shown in Fig. 6. Owing to the vertical and horizontal regularities of the buildings, only one of the inner frames of each structure is analyzed and designed. The buildings are assumed to be located in Los Angeles and with office occupancy. Similar design parameters and loads are considered for the three buildings.

The structures are loaded according to ASCE 7-10 [27]. Dead and live loads are assumed to 
be $5 \mathrm{kN} / \mathrm{m}^{2}$ and $2.4 \mathrm{kN} / \mathrm{m}^{2}$, respectively, for all stories. Seismic design is performed based on the equivalent lateral force analysis. The frames are assumed to be of special moment resisting frames (SMRF) type. In the calculations to follow, $S_{S}$ and $S_{1}$ are the mapped maximum considered earthquake (MCE) spectral response acceleration for site class $\mathrm{B}$ at $0.2 \mathrm{~s}$ and $1 \mathrm{~s}$, respectively; $F_{a}$ and $F_{v}$ are site coefficients for $0.2 \mathrm{~s}$ and $1 \mathrm{~s}$, respectively; $S_{M S}$ and $S_{M 1}$ are the MCE spectral response acceleration parameters at $0.2 \mathrm{~s}$ and $1 \mathrm{~s}$, respectively; $S_{D S}$ and $S_{D 1}$ are the design basis earthquake (DBE) spectral response acceleration parameters at $0.2 \mathrm{~s}$ and $1 \mathrm{~s}$, respectively; $I_{e}$ is the importance factor. The seismic response coefficient $\left(C_{s}\right)$ is calculated as follows,

$S_{S}=2.1 g, S_{1}=0.93 g$, Site Class $D$

$F_{a}=1.0, F_{v}=1.5$

$S_{M S}=F_{a} S_{S}=2.1 \mathrm{~g}$ (peak ground acceleration of $0.84 \mathrm{~g}(2.1 \mathrm{~g} / 2.5)$ for MCE)

$S_{M I}=F_{v} S_{l}=1.4 \mathrm{~g}$

$S_{D S}=2 / 3 S_{M S}=1.40 \mathrm{~g}$ (peak ground acceleration of $0.56 \mathrm{~g}(1.4 \mathrm{~g} / 2.5)$ for DBE)

$S_{D I}=2 / 3 S_{M 1}=0.93 g$

Risk Category $I I \rightarrow I_{e}=1.00$

$R=8.0, \Omega_{0}=3.0, C_{d}=5.5$

$T_{0}=0.2 \frac{S_{D 1}}{S_{D S}}=0.13 \mathrm{sec} ., T_{S}=\frac{S_{D 1}}{S_{D S}}=0.66 \mathrm{sec}$.

The values of seismic response coefficient $\left(C_{s}\right)$ amounts to $0.114,0.0650$ and 0.0616 for the 5-, 10- and 20-story structures, respectively. The vertical distribution exponent $(k)$ for the seismic lateral forces is calculated as $1.25,1.64$ and 2.00 for the three buildings, respectively. The maximum allowable drift ratio based on an elastic analysis, is calculated as follows, $\delta_{\max }=0.02 / C_{d}=0.0036$

Dead and live loads are distributed on beams and earthquake load is applied at the center of mass of each story. The frame models are designed according to AISC 360-10 code [28]. Then, 
the maximum allowable drift ratio is checked and design is revised as necessary. Fig. 7 displays the designed sections for the three buildings.

\subsection{Structural modeling and analysis method}

Analyses are conducted using the Perform 3D [29] nonlinear finite element analysis software. Columns and beams are modeled using frame elements. End offsets are considered at both ends of the elements. Nonlinear behavior of the frame elements is considered through concentrated plastic hinges at both ends of the free length of the frame elements, based on the suggestions of FEMA 356 [30]. The plastic hinges located in columns are assumed to be of type PMM which considers the effect of axial load on plastic moment and plastic rotation capacity. The beams plastic hinges are considered of the simple type, only considering the strong axis moment. The modulus of elasticity, yield stress and Poisson's ratio of the steel material are considered equal to $200 \mathrm{GPa}, 345 \mathrm{MPa}$ and 0.3 , respectively.

DPD devices are modeled using the nonlinear spring (isolator) elements with forcedisplacement relationships calculated as explained in section 2 . The vertical stiffness of the nonlinear spring is considered zero. The DPDs are considered to be installed in the frame after the floors are constructed in order to minimize the vertical displacement due to gravitational loads.

Performance levels of the frame elements are determined according to FEMA 356 [30] acceptance criteria for nonlinear procedures. Hence, three performance levels of Immediate Occupancy (IO), Life Safety (LS) and Collapse Prevention (CP) are considered. When the performance level of a structural member passes the collapse prevention $(\mathrm{CP})$ level during the nonlinear analyses, it is assumed that the performance level of the structure does not meet the acceptance criteria. Hence, continuing the analysis is useless and the analysis is stopped.

A suite of seven earthquake records of different magnitudes, peak ground accelerations (PGAs) and frequency contents are chosen for time-history analyses. The ground motions 
include the Imperial Valley, Chi-Chi, Kobe, San Fernando, Northridge, Landers and Loma

Prieta. All the earthquake records have been selected from PEER ground motion database [31]. Table 1 lists the selected ground motion data. The pseudo-acceleration response spectra of the ground motions are depicted in Fig. 8. Constant viscous damping ratio of 5\% is assumed for all mode shapes in the structural models.

The earthquake excitations are scaled to the design basis earthquake (DBE) and maximum considered earthquake (MCE) levels, according to the ASCE7-10 method of scaling. To scale the ground motions to the DBE level, the ground motions are scaled such that the average value of the 5 percent damped response spectrum for each ground motion is not less than the design response spectrum for periods ranging from $0.2 \mathrm{~T}$ to $1.5 \mathrm{~T}$ [28], where $\mathrm{T}$ is the natural period of the fundamental mode of vibration of the bare frames. The DBE scale factors for different ground motions and structures are listed in Table 2. The scale factors and response spectra of MCE records are considered to be 1.5 times those of the DBE records, according to ASCE7-10 [28].

The inverted-V braces are selected from the HSS European hollow square sections satisfying the stiffness and strength criteria. The frame elements are unchanged in the bare frames and the frames with DPDs in order to maintain the comparability of the models. Based on this assumption, the elevated axial forces in columns due to the DPD forces could damage the columns in buckling mode or lessen the plastic hinge capacity. To avoid this, the DPD braces are positioned such that the columns axial forces are distributed more evenly. Fig. 9 displays the DPD braces configuration in the main frames. It should be noted that changing the number of spans with DPDs does not cause an abrupt change in the stiffness of the story, because the total DPD stiffness of each story is divided among the DPD devices of that story.

\subsection{Parametric study scheme}

It is well-known that the hysteretic dampers should yield before the steel framing to minimize 
the structural damage caused by an earthquake. The lesser the dampers yield displacement are, the sooner they start to dissipate energy during an earthquake, while the frames are still elastic and undamaged. This fact has been approved by several researchers, e.g. [13,24]. Therefore, the yield displacement parameter is not considered in this study, instead, it is set as low as possible. On the other hand, only two of the three possible parameters including yield drift ratio, yield strength ratio and stiffness ratio are independent; as yield displacement, yield strength and stiffness are related through $P_{y}=K . \Delta_{y}$. Having set the yield displacement as low as possible, yield strength will be proportional to the stiffness. Therefore, a one-parameter study is adequate to investigate the performance of the DPDs in steel frames when considering these assumptions.

Some possible story-wise distributions of the passive dampers are: proportional to story stiffness, proportional to story shear, proportional to story drift and constant distribution. Kim and Choi [17], having considered different distributions, concluded that story-wise distribution of passive devices proportional to the story drifts and story shears demonstrated slightly better structural performance. However, the distribution proportional to story stiffness presented an acceptable performance [17]. Moreover, the story-wise drift and shear distributions are load dependent. Therefore, in this paper, the DPDs story-wise distribution is assumed to be proportional to story stiffness, as considered in many other studies, e.g. [13] and [24]. The stiffness parameter used in this study is defined as:

$$
\beta=\frac{K_{D}}{K_{F}}
$$

where $K_{D}$ and $K_{F}$ are the elastic stiffness of the DPD devices in the story and the story frame, respectively. Stiffness parameter, $\beta$, is considered constant in all stories of the buildings and varied from 1 to 10 for the parametric study. However, one should note that by increasing $\beta$, the strength enhancement accompanies the stiffness increase of DPDs.

\section{Design of the DPD}


The most important design parameters for a passive damper are stiffness, strength and yield displacement, among which only two are independent. Herein, we consider having the stiffness and the yield displacement. In addition, the seismic displacement demand must be less than the ultimate tolerable displacement, $\Delta_{u}$, of the DPD device; therefore, $\Delta_{u}$ can be assumed more than or equal to seismic displacement demand. The ultimate tolerable displacement of DPD can be found from $\mu . \Delta_{y}$, in which $\Delta_{y}$ and $\mu$ are calculated from Eq. (1) and Eq. (3), respectively. Therefore $\Delta_{u}$ can be obtained as,

$$
\Delta_{u}=(0.158 D-0.27)\left(\frac{D}{t}\right)^{0.2}
$$

Neglecting -0.27 term and rounding off, the pipes diameter can be obtained from:

$$
D=6 \Delta_{u}\left(\frac{D}{t}\right)^{-0.2}
$$

The length of the DPD device may also be calculated using Eq. (2), having the required stiffness. Therefore, the length of the DPD device $(L)$ can be obtained in mm, as follows,

$$
L=3.17 \times 10^{-4} K_{0}\left(\frac{D}{t}\right)^{3.14}
$$

By substituting the desired $D / t$ value in Eqs. (10) and (11), one can find the length $(L)$ and the diameter $(D)$ of the pipes. Thereafter, pipe thickness $(t)$ can be obtained from the assumed $D / t$ value. The yield displacement of passive dampers should be set to the lowest possible value in order to dissipate the seismic energy as early as possible during an earthquake. The yield displacement of the DPD is proportional to the square of the pipes diameter and inverse of the pipes thickness, as indicated by Eq. (1). So, for DPDs with constant pipes diameter, the DPDs with thicker pipes (lower $D / t$ ratio) yield at lower displacements and dissipate more energy before failure. However, they demonstrate a slightly lower ultimate tolerable displacement. The increase in thickness has a limit though. A $D / t$ ratio equal to 20 is recommended to be incorporated in the design equations, as a value to control low-cycle fatigue effects [11]. 
To obtain pipes diameter, the ultimate tolerable displacement of DPDs $\left(\Delta_{u}\right)$ can be assumed

to be equal to the maximum allowable drift in each story. Obviously, using dampers with displacement capacities larger than that would be ineffectual. However, the diameter of the DPD pipes, calculated on the basis of maximum allowable story drift, can be reduced based on the DPD maximum displacement demand at each story, following an analytical study on a structure at a specific site. Doing this, the DPDs yield displacement decreases and the performance of the structure will be enhanced further.

\subsection{Design of DPDs for the current parametric study}

The DPDs used in the current study are designed using the Eqs. (10) and (11). The ultimate tolerable displacement of the DPDs is set equal to the maximum allowable drift. $D / t$ is considered equal to 20 .

$\delta_{\text {all }}=0.02($ Based on ASCE7-10)

$\Delta_{u}=0.02 h=0.02 \times 360 \mathrm{~cm}=7.2 \mathrm{~cm}$

Eq. (10): $D=6 \times 7.2 \mathrm{~cm} \times(20)^{-0.2} \rightarrow D \approx 24 \mathrm{~cm}$

in which, $\delta_{\text {all }}$ is the maximum allowable story drift ratio and $D$ is the DPD pipes diameter. Having the DPD pipes diameter, the thickness of the pipes is assumed to be $1 / 20$ of the pipes diameter equal to $1.2 \mathrm{~cm}$. As the story height and the maximum allowable story drift is the same for the three structures, the DPD pipes diameter and thickness are considered constant for all the three structures with various $\beta$ s. The total length of the DPDs in each story is calculated using Eq. (11), based on the required stiffness at the story ( $\beta$ multiplied by the story stiffness). The total length of the DPDs added to the frame by adding each $\beta$ value is calculated as 49,186 and $340 \mathrm{~cm}$ for the 5-, 10- and 20-story frames, respectively. For instance, the total length of DPDs used in the 10 -story frame with $\beta$ value of 6 would be $6 \times 186 \mathrm{~cm}=1116 \mathrm{~cm}=11.2 \mathrm{~m}$. The diameter and thickness of the pipes used in this study are not changed during the analyses, so that the DPD yield displacement is constant for structures with different $\beta$ s and as a result, the 
structural responses remain comparable.

\section{Performance of the steel frames equipped with DPD}

Static pushover analyses are performed on the bare frame models and models with $\beta$ equal to 5 and 10. The curves of base shear versus roof displacement are plotted in Fig. 10. As seen in this figure, adding DPD to the frames changes the force-displacement curve to a shape similar to that shown in Fig. 5. The maximum displacement of the frames decreases with adding DPDs, slightly. That is because the main frames are the same for all the structures with the same number of stories in order to preserve comparability. However, such high displacements are not reached in frames with DPDs, because the aim of using DPDs is to control a structure such that the roof displacement demand does not pass the yield displacement.

The stiffness, yield force and strength of the entire system are augmented by increasing the $\beta$ factor, in addition to damping enhancement. However, increasing stiffness is a characteristic of all yielding dissipative devices. The stiffness increase, as expected, leads to a reduction in period of natural vibration modes of a structure. Fig. 11 displays the period of natural vibration modes for the three frames with different $\beta$ s. The number of vibration modes displayed in Fig. 11 corresponds to at least $90 \%$ of the effective structural mass being activated. The strength of the whole system is increased by 1.07-1.44 times that of the bare frame for $\beta=10$ (See Fig. 10); hence, increasing $\beta$ by a notch enhances the strength of the whole system by about $11-14 \%$.

A parametric study is conducted on the models of the three structures with DPDs of various $\beta \mathrm{s}$ and hence yield strengths. The finite element models of the structures with and without the DPD devices are analyzed nonlinearly in Perform 3D [29] computer program, under the two sets of scaled earthquake excitations namely, DBE and MCE records. Different responses including maximum roof displacement, maximum drift ratio, maximum base shear, input energy $\left(E_{I}\right)$, hysteretic energy $\left(E_{H}\right)$ and energy absorbed by the dampers $\left(E_{D}\right)$ are recorded for each structure under each earthquake excitation. 
Fig. 12 displays the roof displacement time-histories of 5-, 10- and 20-story buildings for values of $\beta$ equal to 0 (bare structure), 3, 6 and 9 under the Northridge excitation scaled to the DBE level. As seen in Fig. 12, utilizing DPD devices in the frame structures, for all the three steel frames, causes the oscillations after the main shocks of the earthquake to be damped much more quickly and reduces the residual displacement considerably. The absolute residual displacements and the values normalized to the maximum displacements are displayed in Fig. 13, versus $\beta$. By increasing the DPD strength through enhancing $\beta$, both the absolute and normalized residual displacements decrease up to $\beta=6$ and then increase for $\beta=9$, gently. This is attributed to the relatively high plastic stiffness of structures with $\beta=9$, which prevents the structure from centering.

Fig. 14 shows the maximum roof displacement of the structures with DPD devices under the excitations scaled to the DBE and MCE levels, with various $\beta$ s. Note that the data for the structures with performance levels not satisfying collapse prevention (CP) level are not plotted in the graphs. As seen in Fig. 14, the maximum roof displacement is reduced by increasing DPD yield strength (through $\beta$ ) in most cases. However, the curves for the 5- and 10-story structures (Fig. 14-a, b, d and e) are more descending compared to that for the 20-story structure (Fig. 14-c and f). For some earthquakes such as Landers, Loma Prieta and San Fernando, the maximum tip displacement curves of the 20-story structure (Fig. 14-c and f) are mainly flat and even ascending in some intervals. This can be attributed to the higher natural period of the 20 -story structure which is in the velocity-sensitive region of the spectrum. This means the reduced natural period of the 20-story structure due to added stiffness of DPDs leads to higher spectral acceleration, depending on frequency content, and makes the DPDs less effective in the 20-story structure. The other reason is the overall bending of the structure. The taller and slimmer a building is, the more it oscillates in overall bending mode, and the dampers effectiveness is reduced as a result.

Fig. 15 displays the maximum base shear versus $\beta$. As seen from this figure, enhancing the 
DPD yield strength (through $\beta$ ), increases the base shear slightly in most cases. That's because

which could usually increase the acceleration response, due to the shape of response acceleration spectra of most earthquakes. This added acceleration response increases the inertial forces and as a result the base shear. However, one should note that the base shear increase is not a concern in a structure equipped with passive dampers, rather the input energy (the base shear work on structure) is more meaningful. However, the most important parameter is the energy absorbed by the main frame which is related to the damage imposed on the main frame.

Fig. 16 shows the maximum drift ratio for the three building structures under earthquakes scaled to the DBE and MCE levels in terms of $\beta$. As it is observed in Fig. 16, the drift ratio is decreased by increasing DPD yield strength (through $\beta$ ) mostly; however, in some cases (as seen in Fig. 16-b, c and f) a small increase is seen. The drifts are reduced even in cases where the tip displacement does not decrease significantly with increasing $\beta$ (see Fig. 14). The drift reduction significantly reduces non-structural damage along with $P-\Delta$ effect, which could excess demand on structural members. The reduction of drift ratios is more severe for the 5- and 10-story structures than the 20-story structure, due to the aforementioned reasons.

The ductility demand (peak damper displacement demand divided by $\Delta_{y}$ ) of a yielding damper shows how much the damper has entered the plastic phase. Low ductility demand demonstrates that the nonlinear capacity of the damper is not utilized completely. The distribution of the ductility demand of the DPDs in height for the three structures with $\beta$ equal to 3 (representing low $\beta$ values) and 9 (representing high $\beta$ values) under the DBE and MCE ground motions are displayed in Fig. 17. The maximum DPD ductility demand usually occurs in lower stories. The DPD ductility demand in higher stories of the 10- and 20-story structures with $\beta$ equal to 9 (see Fig.17-f, $\mathrm{h}, \mathrm{j}$ and $\mathrm{l}$ ) are relatively low, while considerable drift ratios are present. This phenomenon is attributed to the pre-mentioned overall bending of the structure. The ductility demand of DPDs for the structures with high $\beta$ values, especially under the DBE 
excitations, are relatively low and the full capacity of the dampers is not utilized in this case.

The hysteretic term of energy, $E_{H}$ in Eq. (5), in structures with passive devices consists of two parts: the cumulative inelastic energy absorbed by the frames, hereinafter called $E_{F}$, and the inelastic energy dissipated by passive devices, called $E_{D}$. Each of the above-mentioned energy terms may be calculated by having the other two, using the following relationship

$$
E_{H}=E_{F}+E_{D}
$$

The cumulative inelastic energy absorbed by the frame, $E_{F}$, is of great importance as it is related directly to the frame global damage. However, the local destructive damages to frame members should also be considered in addition to global damage, through performance level. The frame inelastic energy absorption, $E_{F}$, of the three frames with DPD devices versus $\beta$ are shown in Fig. 18. As it can be observed, the inelastic energy absorbed by the frame decreases quickly by increasing the DPD yield strength (through $\beta$ ) and tends towards zero in most cases. This means that intensive reduction in the frame plastic deformation and damage is obtained by using DPD devices. The plastic deformation and damage to the frames with high $\beta$ values tend to zero under DBE excitations. $E_{F}$ decreases more slowly with increasing DPD yield strength, in the frames under MCE excitations than those under the DBE excitations and in case of 20-story frame than 5- and 10-story; in other words, the frame absorbs less, yet considerable, amount of inelastic energy than the bare frame, in these cases. The most economical DPD scheme corresponds to the point at which $E_{F}$ reduces to zero (or an acceptable minimum), because further enhancing of the damper yield strength is useless. This value corresponds to $\beta=6$ for 5and 10-story frames under DBE excitations and $\beta=9$ under MCE excitations.

The $E_{F}$ is normalized by $E_{F O}$, the bare frame inelastic energy absorption, and the normalized $E_{F} / E_{F 0}$ ratio is presented in Fig. 19. The normalized input energy ratio, $E_{F} / E_{F 0}$, is only calculated for excitations under which the performance level of the bare frame did not pass CP. The normalized $E_{F} / E_{F 0}$ ratio is one of the most meaningful parameters of seismic response of frames with passive dampers, showing the reduction in frame inelastic energy by using the dampers, 
compared to bare frame. Therefore, it is an important measure of frame damage reduction. By increasing the DPD yield strength, a rapid reduction of $E_{F} / E_{F 0}$ for the 5- and 10-story frames under DBE excitations and relatively slow reduction rate in the case of 20-story frame under DBE excitations is observed. The reduction rate is even slower for the 20 -story frame under MCE excitations, shown in Fig. 19-d. The normalized $E_{F} / E_{F 0}$ ratio of the 20 -story frame structure under Kobe excitation goes beyond one for some $\beta \mathrm{s}$, because of the relatively high period, total bending mode displacement and frequency content.

Another way of normalizing the $E_{F}$ is to divide it by $E_{H}$, the total hysteretic energy absorbed by the structure during earthquake excitations. The resulted normalized $E_{F} / E_{H}$ ratios, showing the contribution of frame to the absorbed nonlinear energy, are demonstrated in Fig. 20 versus $\beta$. The less $E_{F} / E_{H}$ ratio demonstrates higher contribution of passive dampers to the total absorbed nonlinear energy. The DPD devices in all the three frames dissipate larger part of the total absorbed inelastic energy at higher $\beta \mathrm{s}$. Just like the $E_{F} / E_{F 0}$ ratio, the $E_{F} / E_{H}$ ratio is bigger for the MCE excitations (Fig.20-d, e and f) than the DBE excitations (Fig.20-a, b and c). The $E_{F} / E_{H}$ ratio tends to zero in all the frames under the DBE excitations, but this is not the case for the 5and 20-story frames under some MCE excitations.

The energy absorbed by a damper, $E_{D}$, can be normalized by $E_{I}$, the total input energy. The normalized $E_{D} / E_{I}$ ratio is calculated and shown in Fig. 21 . The normalized $E_{D} / E_{I}$ ratio shows the contribution of DPDs in total energy input of the structure. As observed in Fig. 21, the $E_{D} / E_{I}$ ratio starts from zero for bare structure and grows to a maximum value of 0.5 to 0.67 for the medium to large $\beta$ values; this means that the DPD devices are capable of dissipating more than half of the total input energy, even in low $\beta$ s. The $E_{D} / E_{I}$ ratios for the structures under MCE excitations are less for low $\beta$ s but more for high $\beta$ s than those under DBE excitations.

The performance level of the frames is also important, as it can show the local damage to frame members. Table 3 displays the performance level of the frames with different $\beta$ s under the DBE excitations. As seen from this table, DPDs improve the performance level of the frames to 
immediate occupancy (IO) at relatively low DPD yield strengths. However, the improvement is

not seen in some cases and occurs at relatively large $\beta$ s in the case of 20-story frame.

\section{Performance of DPD compared to TADAS}

DPDs have a secondary hardening branch in their force-displacement (see Fig. 4) which is a specific characteristic. To evaluate the DPDs performance against other metallic dampers, a comparison is made against TADAS, a well-known metallic damper. The responses of the 10story frame equipped with DPDs with $\beta=3$ are compared with those of the frame equipped with equivalent TADAS devices. Bi-linear force-displacement with post-yield stiffness is assumed for TADAS [5]. The equivalent TADAS device dimensions are considered similar to the TADAS device tested in [5]. The yield strength of the equivalent TADAS device at each story is considered equal to that of the DPDs and the other properties $\left(K_{e}, \Delta_{y}\right.$ and post-yield stiffness) are found using equations given in [5]. For example, the yield displacement of TADAS to be used in force-displacement is calculated to be $6.56 \mathrm{~mm}$.

The two frames, one with DPD and the other one with equivalent TADAS are analyzed and the most important responses are illustrated in Fig. 22. The tip displacement of the frame with DPD is less than that with TADAS under 5 out of 7 earthquakes and slightly more under the 2 remaining. However, the maximum inter-story drift is remarkably less in the frame with DPD, under all earthquakes, meaning less non-structural damage. This is attributed to the second hardening branch of DPD which does not permit the inter-story drift to increase rapidly when the DPD deformation passes $\Delta_{p}$. This added stiffness leads to increased base shear, as seen in Fig. 22. However, one should note that the input energy (the base shear work) is a better measure and yet the most important is the energy absorbed by the plastic action of the frame $\left(E_{F}\right)$, being directly proportional to the frame damage. As seen from Fig. 22, the input energy is slightly lower for the frame with DPD than that with TADAS, under 5 out of 7 earthquakes and slightly higher under the 2 remaining. The $E_{F}$ is considerably lower for the frame with DPD, 
under all the earthquakes, which translates to lower damage to the main frame. Also DPDs absorb a higher portion of input energy $\left(E_{I}\right)$ than the equivalent TADAS devices, as $E_{D} / E_{I}$ is higher for the frame with DPD than that with TADAS, under all the earthquakes.

\section{Summary and conclusion}

Guidelines for implementing dual pipe dampers (DPDs) in steel buildings were presented in this paper. A representative load-displacement model of the DPD was proposed for the first time. Design recommendations and formulation for DPDs were also presented.

5-, 10- and 20-story steel moment resisting frames were designed without dampers first and then equipped with DPDs of different strength. The DPD pipe diameter was selected based on the maximum allowable drift of each story. The responses of the frames without and with DPDs to seven earthquake excitations, scaled to the DBE and MCE levels, were investigated. The results of the study proved that DPDs are capable of significantly reducing the structural and non-structural seismic damages and increasing the seismic reliability of structures. Comparison between seismic responses of a 10-story frame equipped with DPD and that with equivalent TADAS was performed. The following conclusions can be drawn:

1. The inelastic energy absorbed by the main frames decreases quickly by increasing the DPD yield strength and tends towards zero or a relatively low value under DBE. This translates to no damage or limited damage to the main frame. However, for the frames under MCE, there are some level of damage in some cases, especially for the 20-story frame. The most economical DPD scheme corresponds to a system for which $E_{F}$ reduces to zero or an acceptable minimum.

2. Maximum tip displacement is reduced by an average of $70.0 \%, 69.4 \%$ and $36.0 \%$ in models with maximum DPD strength compared to bare frames, for the 5-, 10- and 20-story frames.

3. The DPDs are less effective in reducing seismic responses of the 20-story structure than the 5- and 10- story structures due to the higher natural period and the overall bending mode 
deformation of the taller building.

4. DPDs absorb a large portion of input energy. This is higher for MCE excitations than DBE. The maximum ratio of damper energy to input energy also occurs at a lower DPD strength under DBE excitations. For the10-story frame, this ratio amounts to 0.673 at $\beta=9$ for MCE, compared to 0.620 at $\beta=5$ for DBE.

5. DPDs improve the performance level of the frames to immediate occupancy (IO) at relatively low DPD yield strengths, in most cases under DBE. This is not true for the taller 20-story frame.

6. The DPD, having a specific secondary hardening portion in force-displacement, absorbs higher energy and imposes less structural damage to the frame compared to equivalent TADAS.

7. Adding the DPD devices to frames significantly decreases the non-structural damage by limiting the inter-story drifts. Maximum inter-story drift is remarkably less in the frame with DPD compared to that with equivalent TADAS. This is due to the secondary hardening branch of force-displacement which does not permit the inter-story drift to increase rapidly.

\section{Acknowledgement}

This research was partially funded by the Iran National Science Foundation (Project No. 88001905). Their support is gratefully acknowledged.

\section{References}

[1] Housner GW, Bergman LA, Caughey TK, Chassiakos AG, Claus RO, Masri SF, Skelton RE, Soong TT, Spencer BF, Yao JT. Structural control: past, present, and future. J Eng Mech 1997; 123(9):897-971.

[2] Soong TT, Dargush GF. Passive energy dissipation systems in structural engineering. John Wiley \& Sons; 1997.

[3] Kelly JM, Skinner RI, Heine AJ. Mechanisms of energy absorption in special devices for use in earthquake-resistant structures. Bull New Zealand Nat Soc Earthq Eng 1972; 5(3):63-88.

[4] Bergman DM, Goel SC. Evaluation of cyclic testing of steel plate devices for added damping 
and stiffness. Report No. UMCE87-10. MI, USA: The University of Michigan; 1987.

[5] Tsai K, Chen H, Hong C, Su Y. Design of steel triangular plate energy absorbers for seismicresistant construction. Earthq Spectra 1993; 9(3):505-528.

[6] Kobori T, Miura Y, Fukusawa E, Yamada T, Arita T, Takenake Y, Miyagawa N, Tanaka N, Fukumoto T. Development and application of hysteresis steel dampers. Proceedings of the 11th world conference on earthquake engineering. 23-28 June 1996, Acapulco, Mexico; 1996. p. 2341-2346.

[7] Nakashima M, Iwai S, Iwata M, Takeuchi T, Konomi S, Akazawa T, Saburi K. Energy dissipation behaviors of shear panels made of low yield steel. Earthq Eng Struct Dyn 1994; 23:1299-1313.

[8] Iwata M, Kato T, Wada A. Buckling-restrained braces as hysteretic dampers. Behavior of Steel Structures in Seismic Areas, STESSA 2000; 33-38.

[9] Maleki S, Bagheri S. Pipe damper, Part I: Experimental and analytical study. J Constr Steel Res 2010; 66:1088-1095.

[10] Maleki S, Bagheri S. Pipe damper, Part II: Application to bridges. J Constr Steel Res 2010; 66:1096-1106.

[11] Maleki S, Mahjoubi S. Dual-pipe damper. J Constr Steel Res 2013; 85:81-91.

[12] Maleki S, Mahjoubi S. Infilled-pipe damper. J Constr Steel Res 2014; 98:45-58.

[13] Xia C, Hanson R. Influence of ADAS element parameters on building seismic response. J Struct Eng 1992; 118(7):1903-1918.

[14] Curadelli RO, Riera JD. Reliability based assessment of the effectiveness of metallic dampers in buildings under seismic excitations. Eng Struct 2004; 26:1931-1938.

[15] Nakashima M, Saburi K, Tsuji B. Energy input and dissipation behaviour of structures with hysteretic dampers. Earthq Eng Struct Dyn 1996; 25:483-496.

[16] Madsen LPB, Thambiratnam DP, Perera NJ. Seismic response of building structures with dampers in shear walls. Comput Struct 2003; 81(4):239-253.

[17] Kim J, Choi H. Behavior and design of structures with buckling-restrained braces. Eng Struct $2004 ; 26: 693-706$.

[18] Clark PW, Aiken ID, Ko E, Kasai K, Kimura I. Design procedures for buildings incorporating hysteretic damping devices. In: Proceedings, 68th annual convention, structural engineers association of California. Santa Barbara (California): 1999.

[19] Kim J, Seo Y. Seismic design of low-rise steel frames with buckling-restrained braces. Eng Struct 2004; 26(5):543-51.

[20] Ma CF, Zhang YH, Tan P, Kennedy D, Williams FW, Zhou F L. Non-stationary seismic 
response analysis of base-isolated buildings with many hysteretic devices. Comput Struct 2013; 123:39-47.

[21] Moreschi LM, Singh MP. Design of yielding metallic and friction dampers for optimal seismic performance. Earthq Eng Struct Dyn 2003; 32(8):1291-1311.

[22] Chang KC, Soong TT, Oh ST, Lai ML. Seismic behavior of steel frame with added viscoelastic dampers. J Struct Eng 1995; 121(10):1418-1426.

[23] Lin YY, Tsai MH, Hwang JS, Chang KC. Direct displacement-based design for building with passive energy dissipation systems. Eng Struct 2003; 25:25-37.

[24] Oviedo A JA, Midorikawa M, Asari T. Earthquake response of ten-story story-driftcontrolled reinforced concrete frames with hysteretic dampers. Eng Struct 2010; 32(6): 1735-1746.

[25] Uang CM, Bertero VV. Evaluation of seismic energy in structures. Earthq Eng Struct Dyn 1990, 19(1):77-90.

[26] Constantinou MC, Symans MD. Seismic response of structures with supplemental damping. The Struct Des Tall Build 1993; 2:77-92.

[27] ASCE 7-10. Minimum design loads for buildings and other structures. American Society of Civil Engineers ASCE/SEI; 2011.

[28] AISC 360-05. Specification for structural steel buildings. American Institute of Steel Construction ANSI/AISC; 2005.

[29] Computers and Structures, Inc. PERFORM 3D: nonlinear analysis and performance assessment for 3D structures. Version 5.0.0. Berkeley (CA); 2011.

[30] FEMA-356. Prestandard and commentary for the seismic rehabilitation of buildings. Federal Emergency Management Agency; 2000.

[31] Pacific Earthquake Engineering Research Center (PEER). Web-Based PEER Ground Motion Database (Beta Version). Berkeley (CA); 2010.

http://peer.berkeley.edu/peer_ground_motion_databas, 12/5/2013. 
Table 1. Selected earthquake ground motions data

\begin{tabular}{|c|c|c|c|c|c|c|c|}
\hline Event name & Station & Year & Magnitude & $\begin{array}{l}\text { Component } \\
\text { (degree) }\end{array}$ & $\begin{array}{l}\text { Dominant } \\
\text { period (sec.) }\end{array}$ & $\begin{array}{l}\text { PGA } \\
(\mathrm{g})\end{array}$ & $\begin{array}{l}\mathrm{PGV} \\
\left(\mathrm{cm} / \mathrm{s}^{2}\right)\end{array}$ \\
\hline $\begin{array}{l}\text { Imperial } \\
\text { Valley }\end{array}$ & $\begin{array}{l}\text { Ec Meloland } \\
\text { Overp. FF }\end{array}$ & 1979 & 6.53 & 270 & 1.707 & 0.296 & 90.4 \\
\hline Chi-Chi & TCU068 & 1999 & 7.62 & 90 & 2.643 & 0.566 & 176.7 \\
\hline Kobe & Takatori & 1995 & 6.90 & 0 & 1.241 & 0.611 & 127.2 \\
\hline $\begin{array}{c}\text { San } \\
\text { Fernando }\end{array}$ & Pacoima Dam & 1971 & 6.61 & 164 & 0.394 & 1.226 & 112.5 \\
\hline Landers & Joshua Tree & 1992 & 7.28 & 0 & 0.738 & 0.274 & 27.5 \\
\hline Loma Prieta & Gilroy Array \#2 & 1989 & 6.93 & 90 & 1.462 & 0.322 & 39.1 \\
\hline Northridge & $\begin{array}{c}\text { Sylmar-Converter } \\
\text { Sta. }\end{array}$ & 1994 & 6.69 & 52 & 1.138 & 0.613 & 117.4 \\
\hline
\end{tabular}

Table 2. DBE scale factors for earthquake ground motions used in the analyses

\begin{tabular}{cccc}
\hline Ground motion & 5-Story Structure & 10-Story Structure & 20-Story Structure \\
\hline Imperial Valley & 2.129 & 1.651 & 1.233 \\
Chi-Chi & 1.111 & 1.005 & 0.823 \\
Kobe & 0.701 & 0.603 & 0.631 \\
San Fernando & 0.831 & 0.864 & 1.04 \\
Landers & 1.848 & 1.864 & 1.885 \\
Loma Prieta & 1.811 & 1.751 & 2.074 \\
Northridge & 0.903 & 0.871 & 0.726 \\
\hline
\end{tabular}


Table 3. Performance level of the frames with different $\beta$ s under the DBE excitations.

1

\begin{tabular}{|c|c|c|c|c|c|c|c|c|c|c|c|c|}
\hline \multirow{2}{*}{ Frame } & \multirow{2}{*}{ Earthquake } & \multicolumn{11}{|c|}{$\beta$} \\
\hline & & 0 & 1 & 2 & 3 & 4 & 5 & 6 & 7 & 8 & 9 & 10 \\
\hline \multirow{7}{*}{$\begin{array}{l}\overrightarrow{0} \\
\text { के } \\
\text { in }\end{array}$} & Imperial Valley & LS & LS & LS & LS & LS & LS & LS & LS & LS & $\mathrm{IO}$ & $\mathrm{IO}$ \\
\hline & Chi-Chi & LS & LS & LS & LS & LS & LS & LS & LS & LS & IO & IO \\
\hline & Kobe & LS & LS & LS & LS & LS & LS & LS & $\mathrm{IO}$ & IO & IO & $\mathrm{IO}$ \\
\hline & San Fernando & LS & LS & LS & LS & LS & IO & IO & $\mathrm{IO}$ & IO & IO & $\mathrm{IO}$ \\
\hline & Landers & LS & LS & LS & LS & LS & LS & LS & $\mathrm{IO}$ & IO & IO & $\mathrm{IO}$ \\
\hline & Loma Prieta & $\mathrm{LS}$ & $\mathrm{LS}$ & LS & LS & LS & LS & IO & $\mathrm{IO}$ & IO & IO & $\mathrm{IO}$ \\
\hline & Northridge & $>\mathrm{CP}$ & $\mathrm{CP}$ & LS & LS & LS & LS & LS & LS & IO & IO & $\mathrm{IO}$ \\
\hline \multirow{7}{*}{$\begin{array}{l}\overrightarrow{0} \\
\text { के } \\
\text { के } \\
\text { d }\end{array}$} & Imperial Valley & $>\mathrm{CP}$ & $>\mathrm{CP}$ & $\mathrm{CP}$ & LS & LS & LS & LS & IO & IO & IO & $\mathrm{IO}$ \\
\hline & Chi-Chi & $>\mathrm{CP}$ & $\mathrm{CP}$ & $\mathrm{CP}$ & $\mathrm{LS}$ & LS & LS & $\mathrm{IO}$ & IO & IO & IO & IO \\
\hline & Kobe & LS & LS & LS & $\mathrm{LS}$ & LS & LS & IO & IO & IO & IO & IO \\
\hline & San Fernando & LS & LS & LS & LS & LS & LS & LS & IO & IO & IO & IO \\
\hline & Landers & LS & LS & LS & LS & LS & IO & IO & IO & IO & IO & IO \\
\hline & Loma Prieta & $\mathrm{CP}$ & $\mathrm{CP}$ & LS & LS & LS & LS & LS & IO & IO & IO & IO \\
\hline & Northridge & LS & LS & $\mathrm{LS}$ & LS & LS & LS & IO & IO & IO & IO & $\mathrm{IO}$ \\
\hline \multirow{7}{*}{ 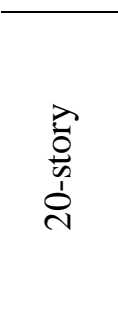 } & Imperial Valley & LS & LS & LS & LS & LS & LS & LS & LS & LS & $\mathrm{IO}$ & $\mathrm{IO}$ \\
\hline & Chi-Chi & $\mathrm{CP}$ & $\mathrm{CP}$ & LS & LS & LS & LS & LS & LS & IO & IO & $\mathrm{IO}$ \\
\hline & Kobe & LS & LS & LS & LS & LS & LS & LS & LS & LS & IO & $\mathrm{IO}$ \\
\hline & San Fernando & LS & LS & LS & LS & LS & LS & LS & LS & LS & LS & LS \\
\hline & Landers & LS & LS & LS & LS & LS & LS & LS & LS & LS & IO & IO \\
\hline & Loma Prieta & LS & LS & LS & LS & LS & LS & LS & LS & LS & LS & LS \\
\hline & Northridge & LS & LS & LS & $\mathrm{LS}$ & LS & LS & LS & IO & IO & IO & IO \\
\hline
\end{tabular}




\section{Figure Captions}

Fig. 1. a) Dual-pipe damper configuration; and b) Installation configuration for DPD.

Fig. 2. Deformed shape of a DPD specimen with $110 \mathrm{~mm}$ diameter and $4.1 \mathrm{~mm}$ thickness.

Fig. 3. Simplified trilinear characteristic force-displacement of the DPD device.

Fig. 4. Simplified trilinear model representing nonlinear behavior of the DPD device along with the experimental hysteresis of DPDs: a) M1L100 specimen; and b) M3L50 specimen.

Fig. 5. The simplified strength-displacement curve for the entire system of a structure with DPD devices.

Fig. 6. Plans of the three building structures analyzed in this study: a) 5-story frame; and b) 10and 20-story frames.

Fig. 7. The designed member sections for the three frames: a) 5-story frame; b) 10-story frame; and c) 20-story frame.

Fig. 8. Unscaled pseudo-acceleration spectra of the earthquake excitations used in this study.

Fig. 9. The DPD braces configuration in the main frames: a) 5-story frame; b) 10-story frame; and c) 20-story frame.

Fig. 10. Nonlinear pushover curves: a) 5-story frame; b) 10-story frame; and c) 20-story frame.

Fig. 11. Period of the natural vibration modes of the structures corresponding to at least $90 \%$ of the structural mass: a) 5-story structure; b) 10-story structure; and c) 20-story structure.

Fig. 12. The roof displacement time-history of the building structures for different $\beta$ values under the Northridge earthquake excitation scaled to DBE: a) 5-story frame; b) 10-story frame; and c) 20-story frame.

Fig. 13. The absolute and normalized residual displacements of the structures under Northridge excitation: a) absolute residual displacements; and b) normalized residual displacements.

Fig. 14. Maximum roof displacement of the frame structures: a) 5-story frame-DBE; b) 10-story frame -DBE; c) 20-story frame -DBE; d) 5-story frame -MCE; e) 10-story frame-MCE; and f) 20-story frame -MCE. 
Fig. 15. Maximum base shear: a) 5-story frame -DBE; b) 10-story frame -DBE; c) 20-story

\section{frame-DBE; d) 5-story frame-MCE; e) 10-story frame -MCE; and f) 20-story frame-MCE.}

Fig. 16. Maximum drift ratio: a) 5-story frame -DBE; b) 10-story frame-DBE; c) 20-story frame -DBE; d) 5-story frame -MCE; e) 10-story frame -MCE; and f) 20-story frame -MCE.

Fig. 17. The height-wise distribution of maximum DPD ductility demand: a) 5-story frame $\mathrm{DBE}, \beta=3$; b) 5 -story frame -DBE, $\beta=9$; c) 5 -story frame -MCE, $\beta=3$; d) 5 -story frame -MCE, $\beta=9$; e) 10 -story frame -DBE, $\beta=3$; f) 10-story frame -DBE, $\beta=9$; g) 10-story frame -MCE, $\beta=3$; h) 10 -story frame -MCE, $\beta=9$; i) 20-story frame -DBE, $\beta=3$; j) 20-story frame -DBE, $\beta=9$; k) 20-story frame-MCE, $\beta=3$; and l) 20-story frame -MCE, $\beta=9$;

Fig. 18. Cumulative inelastic energy absorbed by the frames: a) 5-story frame -DBE; b) 10-story frame -DBE; c) 20-story frame -DBE; d) 5-story frame-MCE; e) 10-story frame-MCE; and f) 20-story frame -MCE.

Fig. 19. Normalized cumulative inelastic energy absorbed by the frames, $E_{F} / E_{F 0}$ : a) 5 -story frame-DBE; b) 10-story frame -DBE; c) 20-story frame -DBE; and d) 20-story frame-MCE.

Fig. 20. Cumulative inelastic energy absorbed by the frames normalized by total hysteretic energy, $E_{F} / E_{H}$ : a) 5 -story frame -DBE; b) 10 -story frame -DBE; c) 20-story frame -DBE; d) 5story frame -MCE; e) 10-story frame-MCE; and f) 20-story frame -MCE.

Fig. 21. Energy dissipated by DPD devices normalized by the input energy, $E_{D} / E_{I}$ : a) 5 -story frame -DBE; b) 10-story frame -DBE; c) 20-story frame -DBE; d) 5-story frame -MCE; e) 10story frame -MCE; and f) 20-story frame -MCE.

Fig. 22. Comparison of the seismic responses of the 10-story frame with DPD $(\beta=3)$ against those of the frame with equivalent TADAS. 


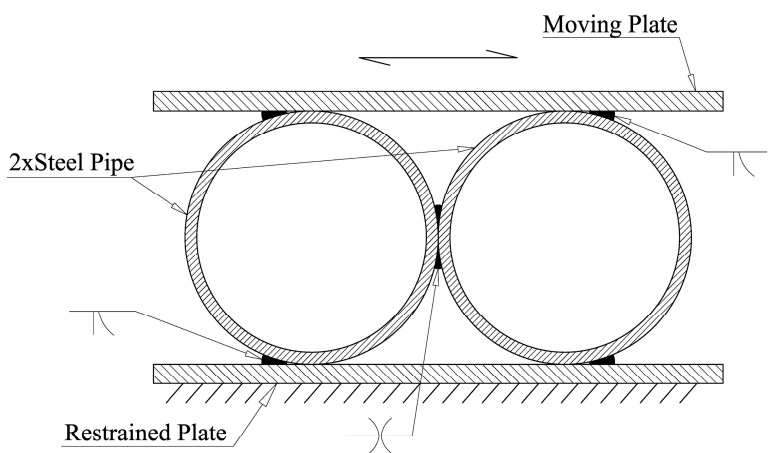

a

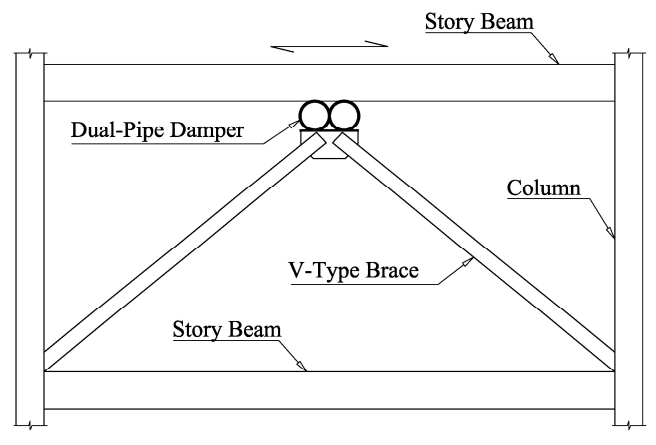

b

Figure 1

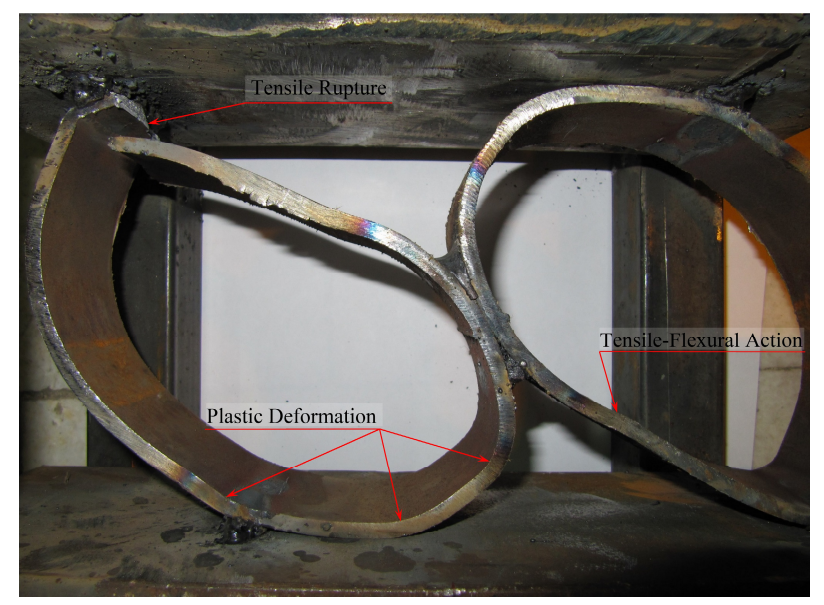

Figure 2

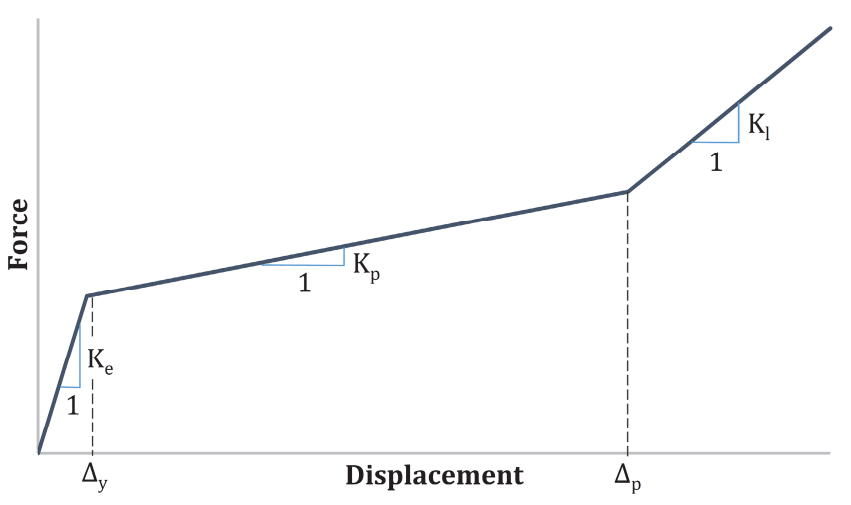

Figure 3
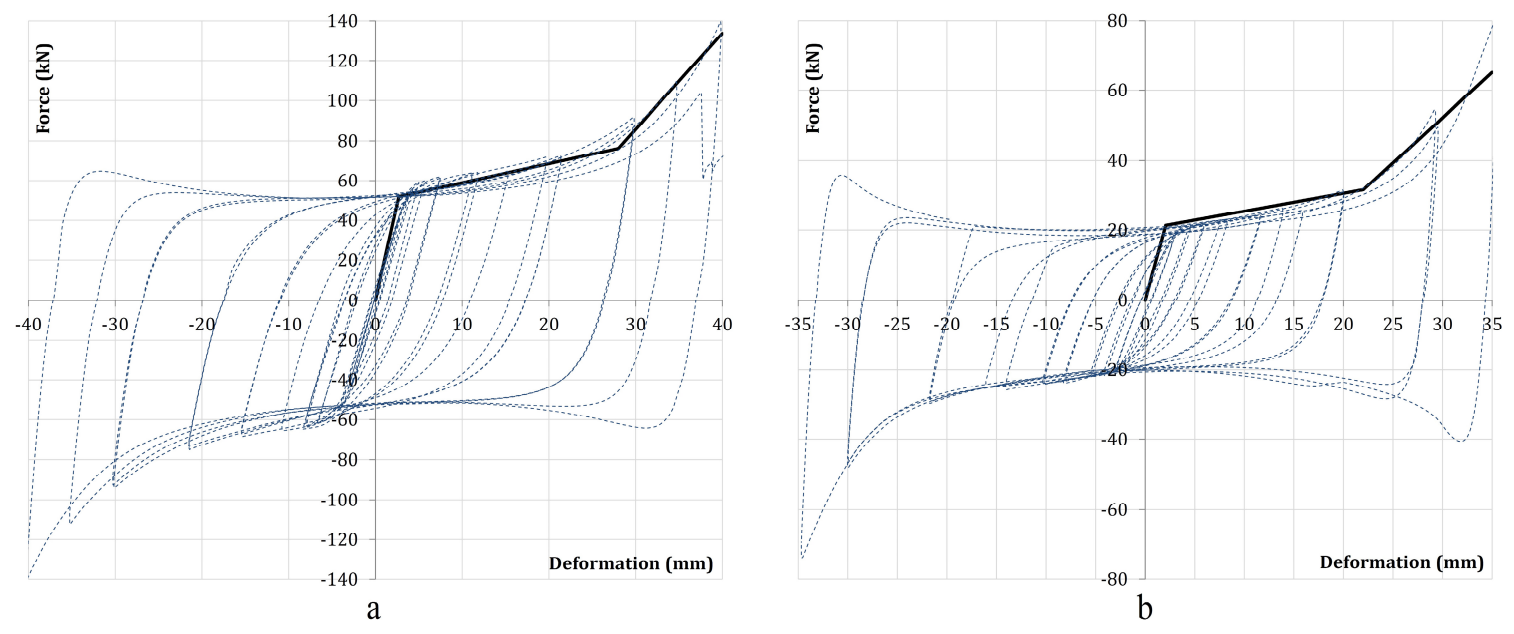

Figure 4 

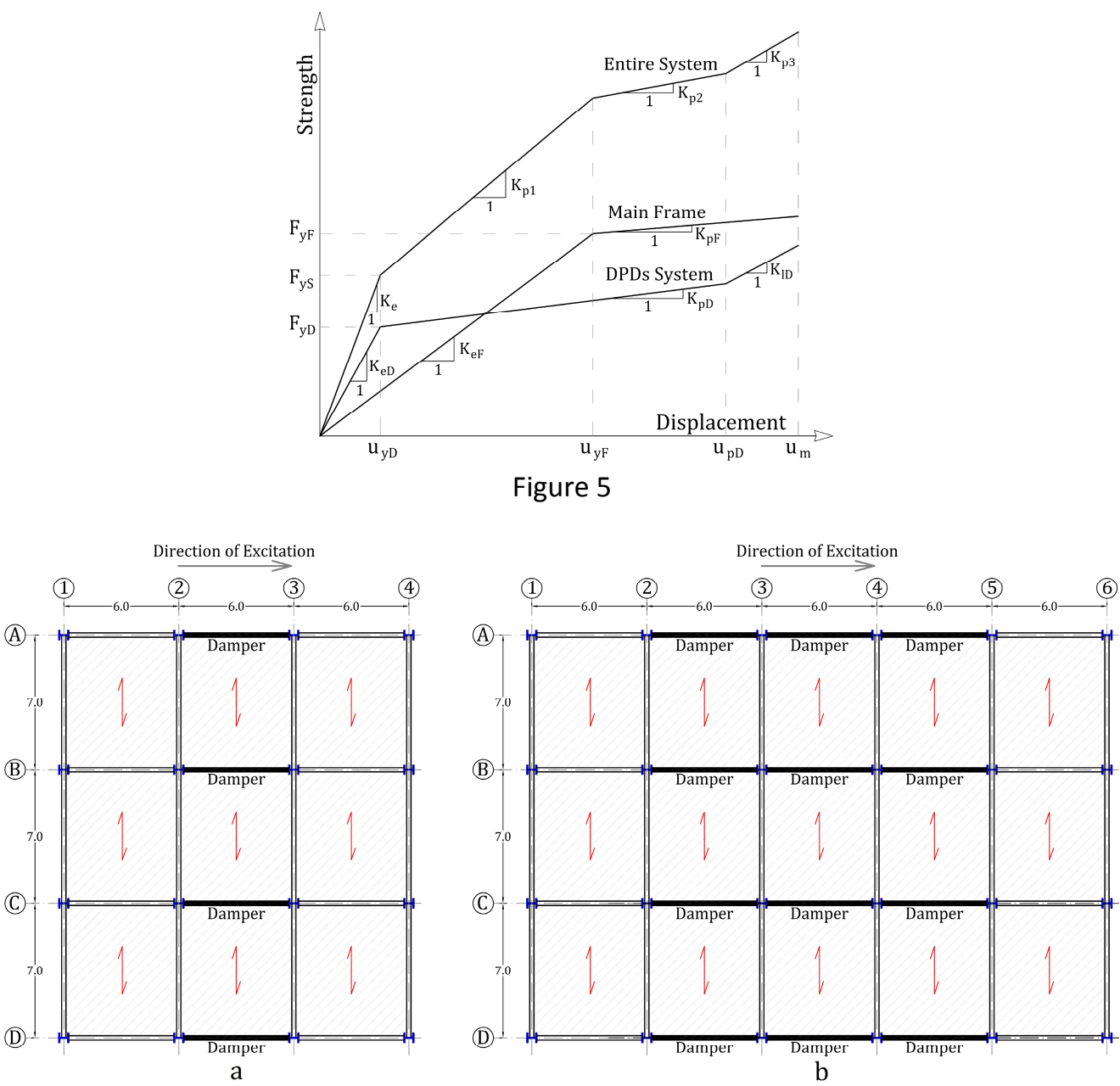

Figure 6
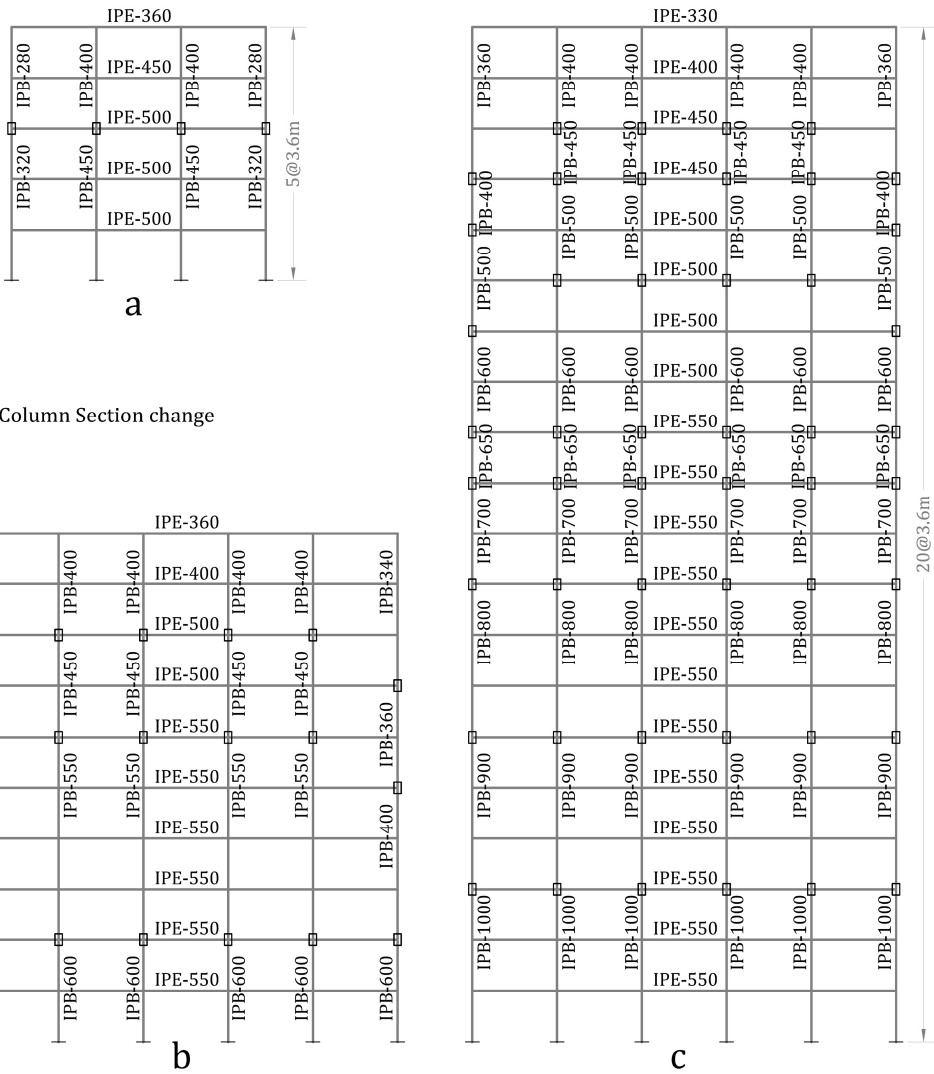

Figure 7 


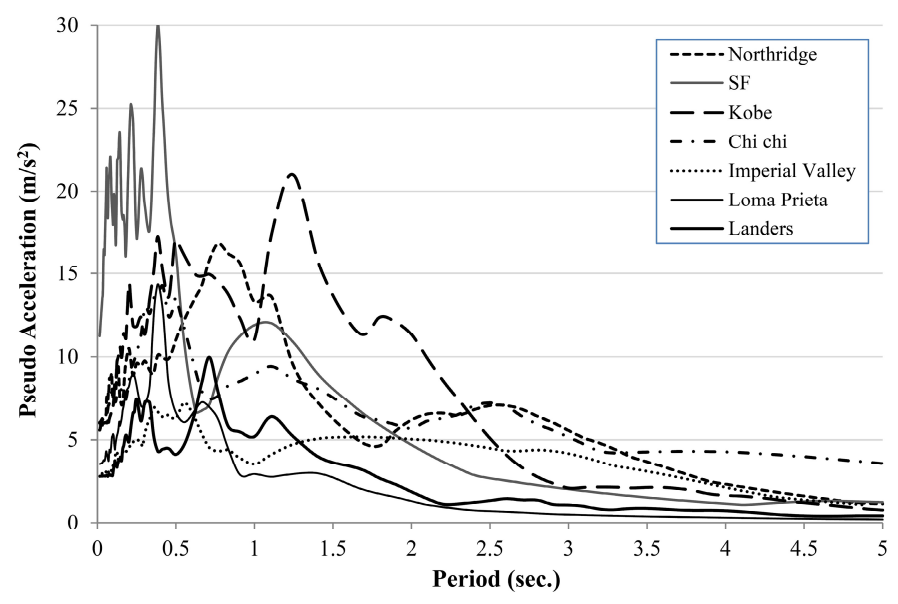

Figure 8

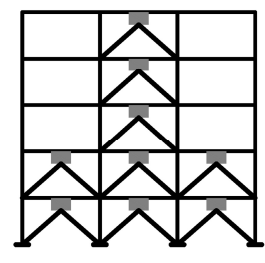

a

- DPD Device
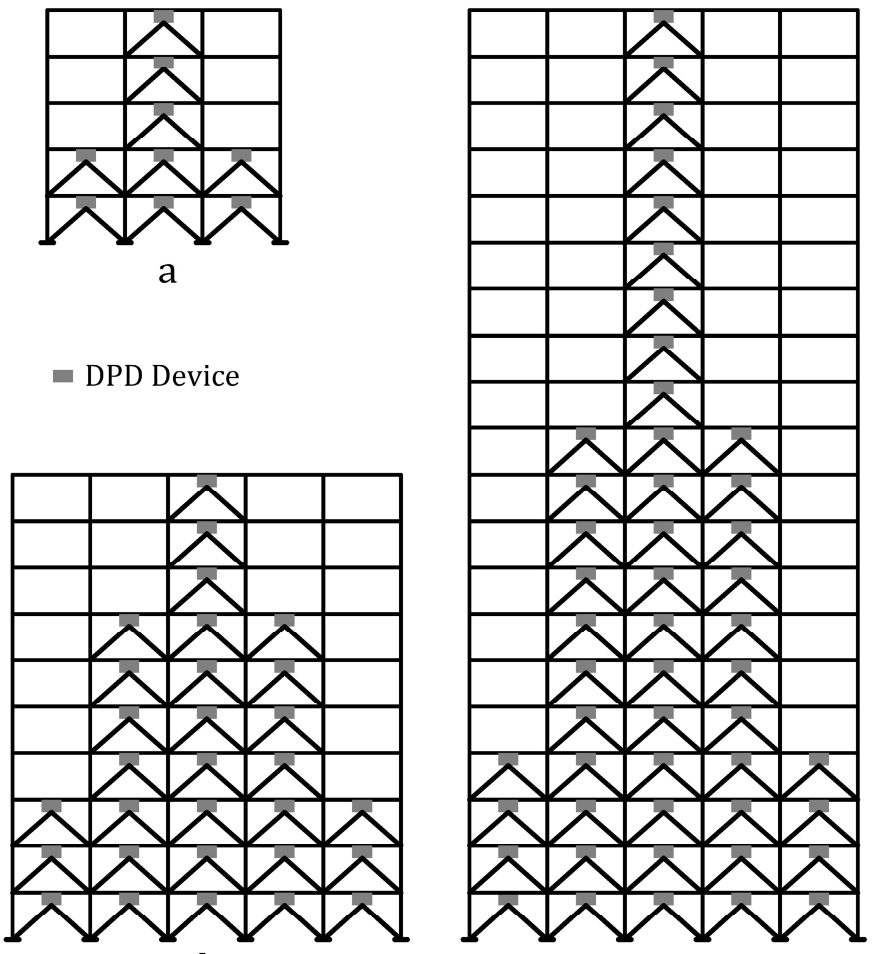

b

Figure 9
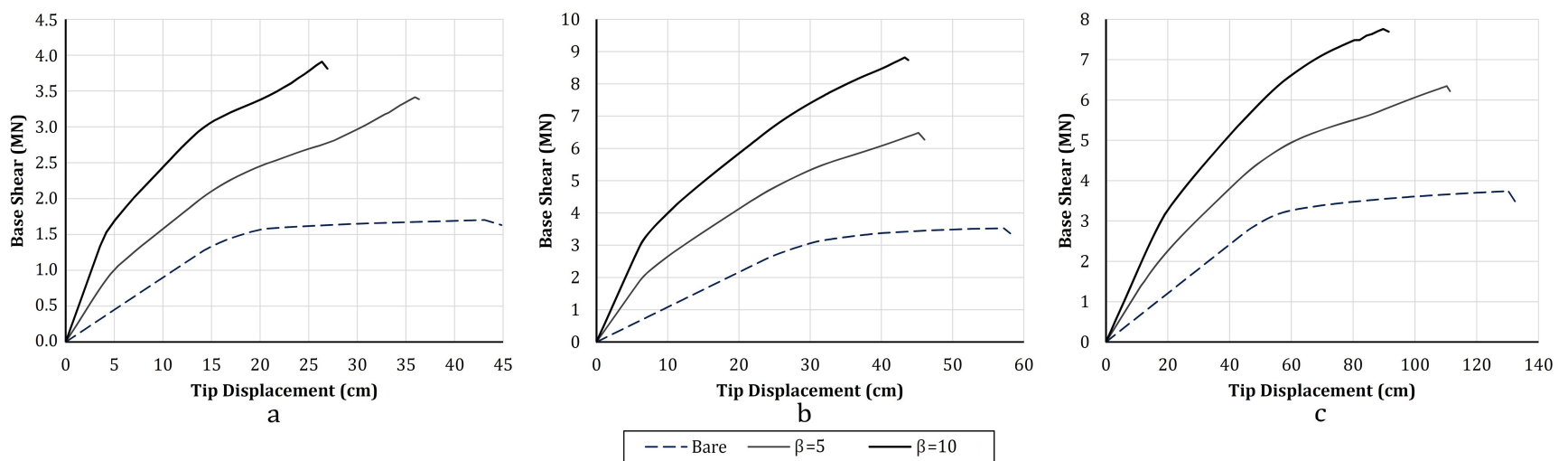

Figure 10 

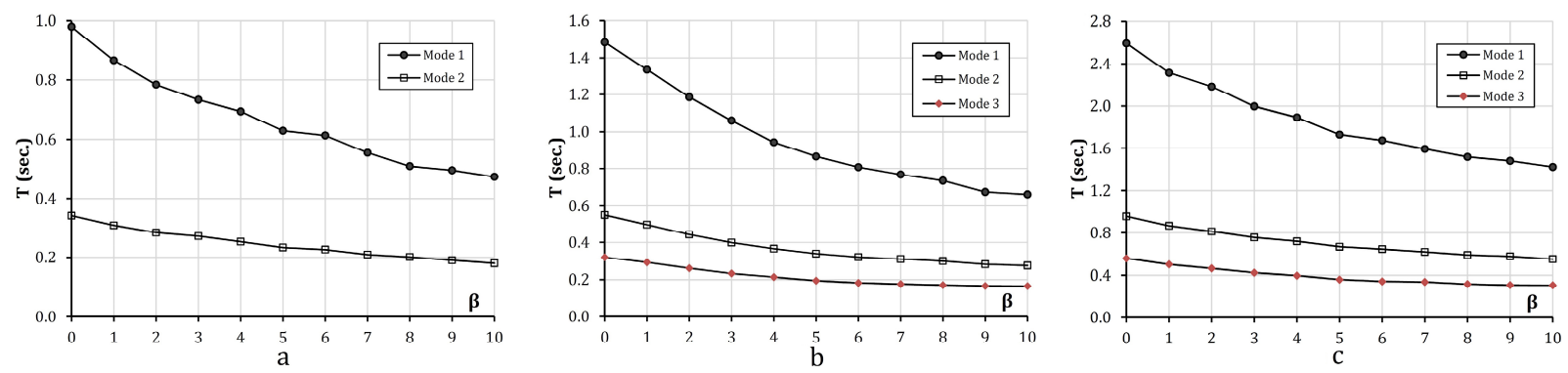

Figure 11
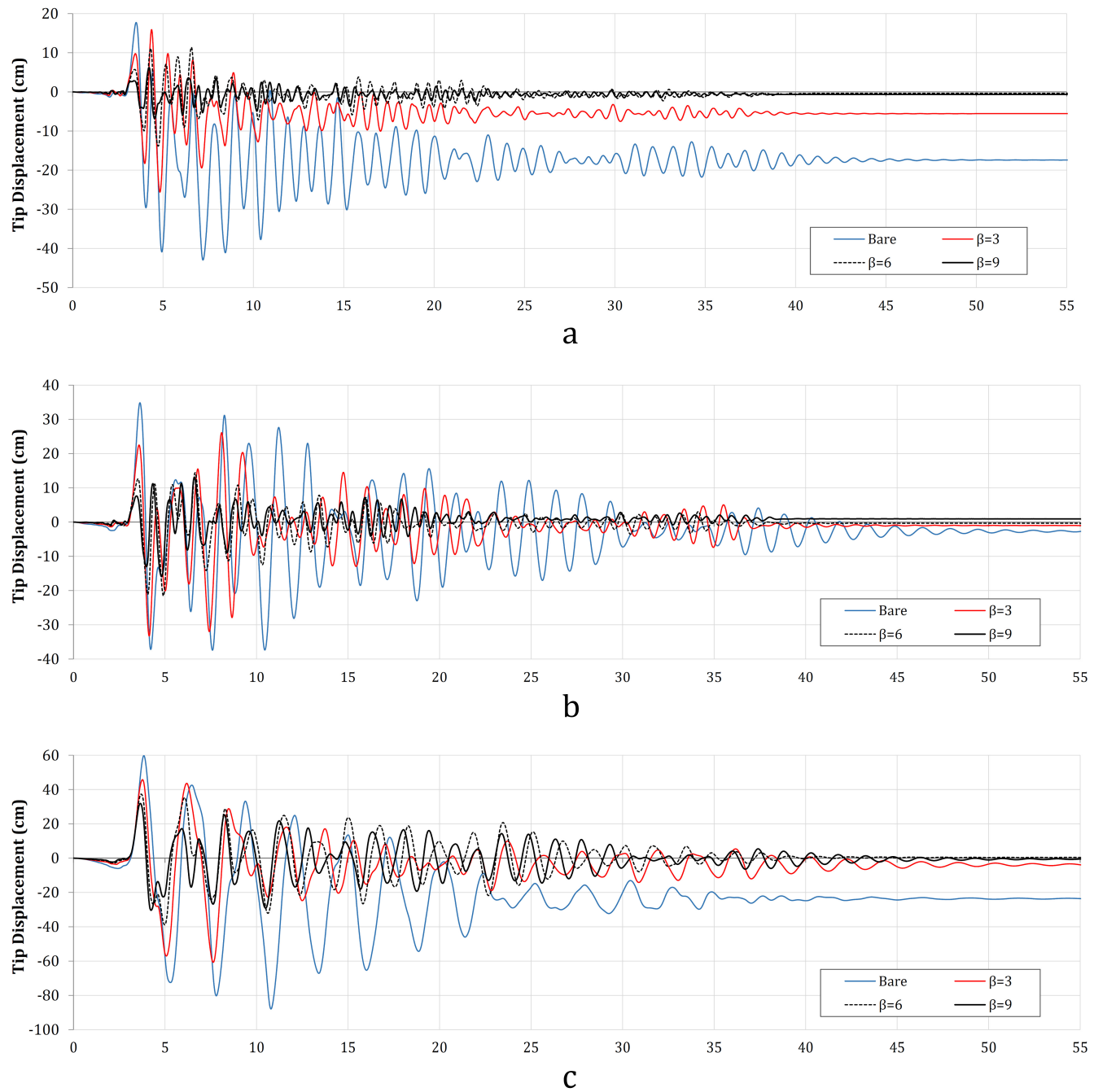

Figure 12
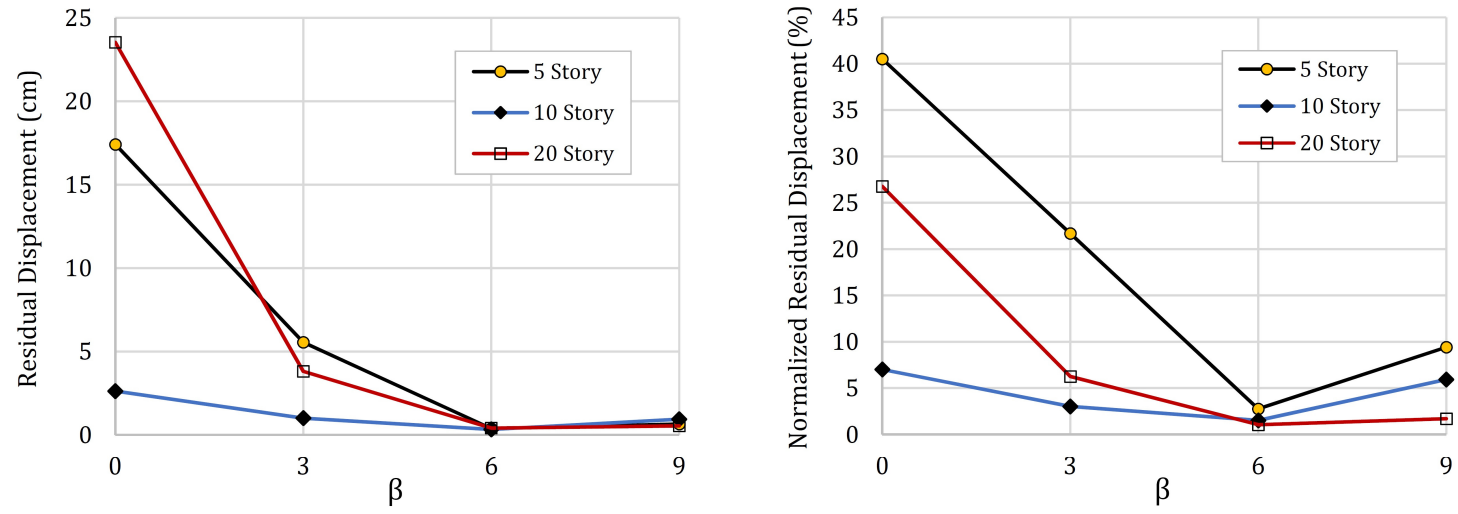

Figure 13 

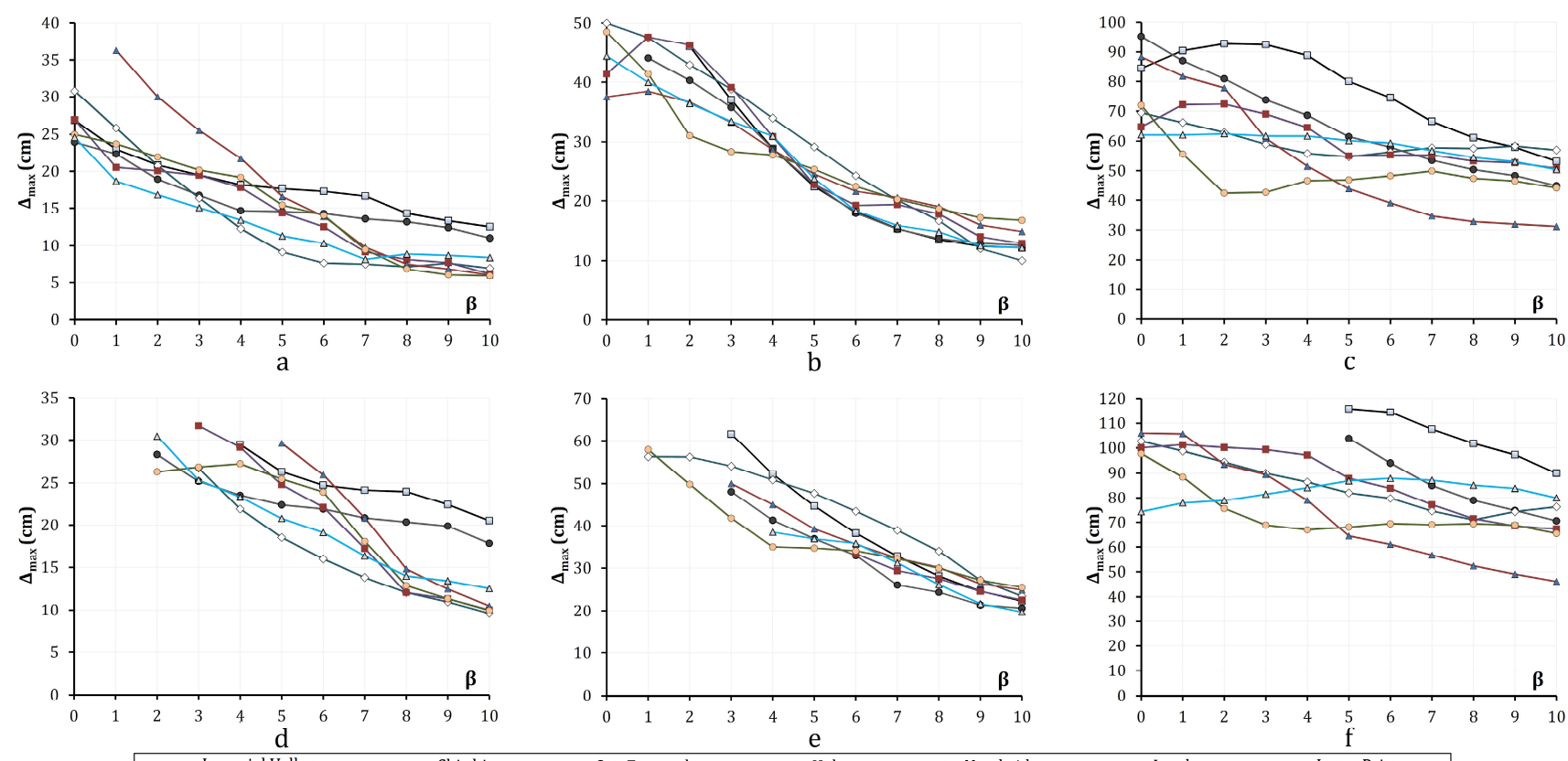

Figure 14
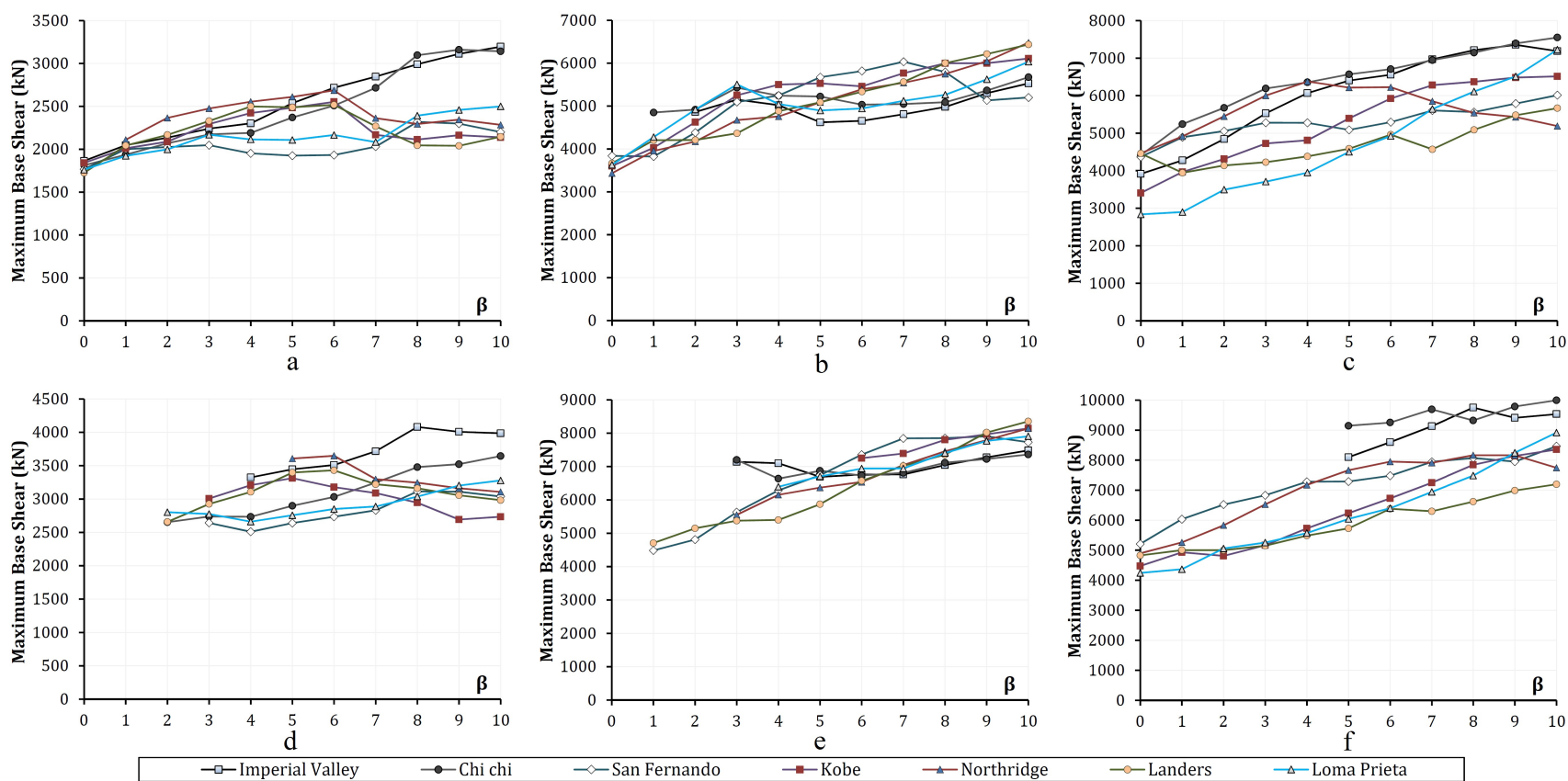

Figure 15 

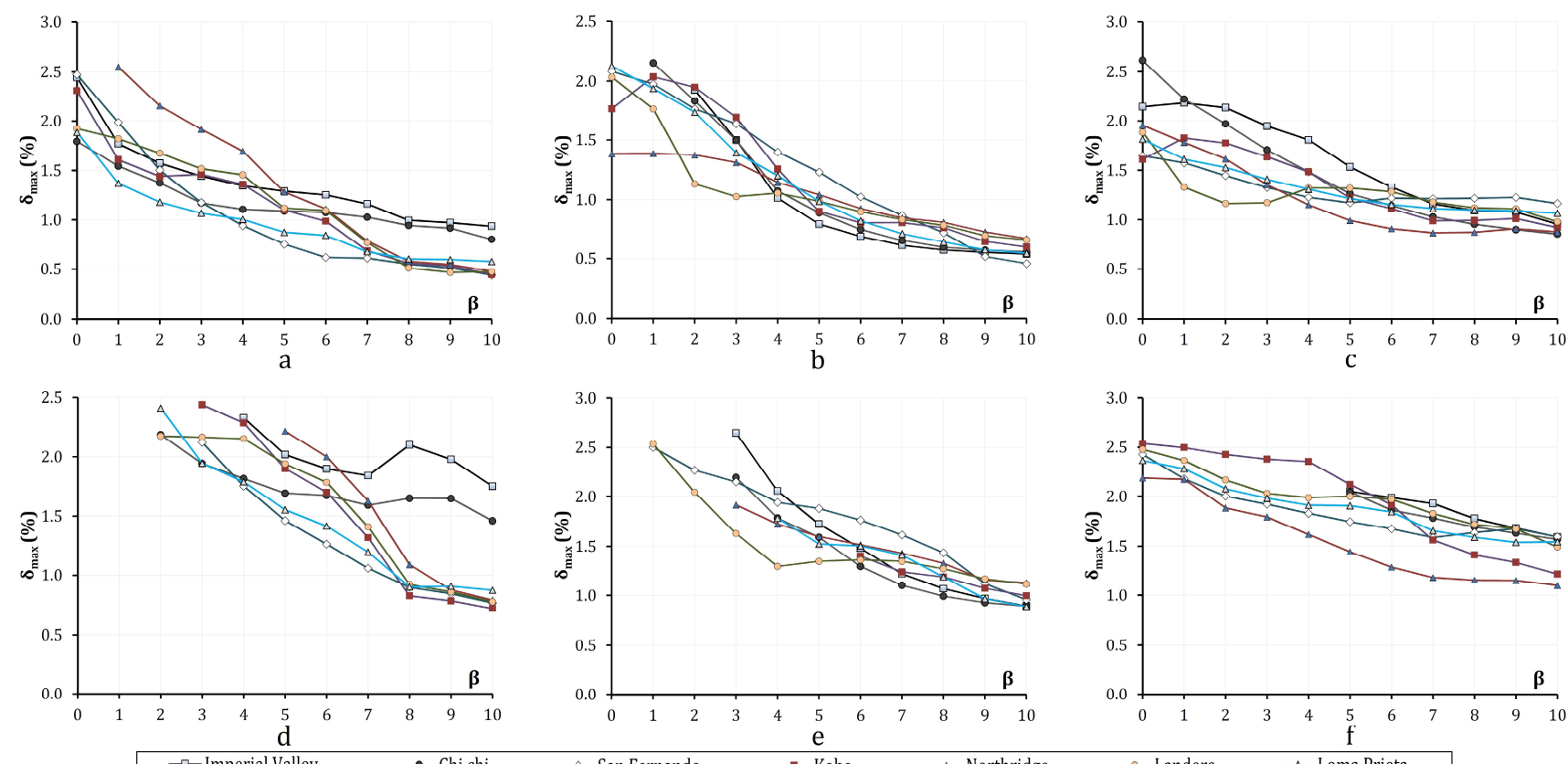

Figure 16
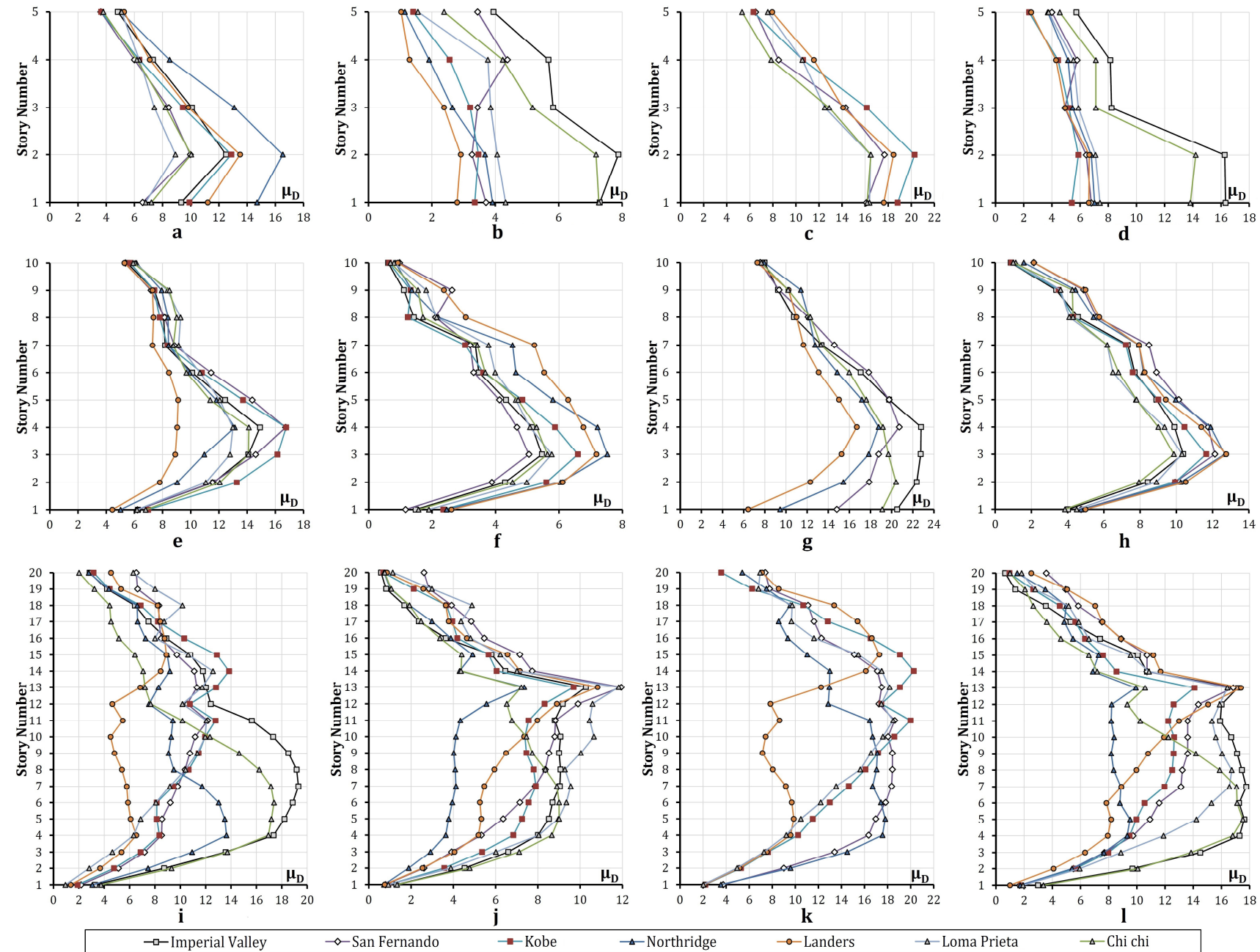

Figure 17 

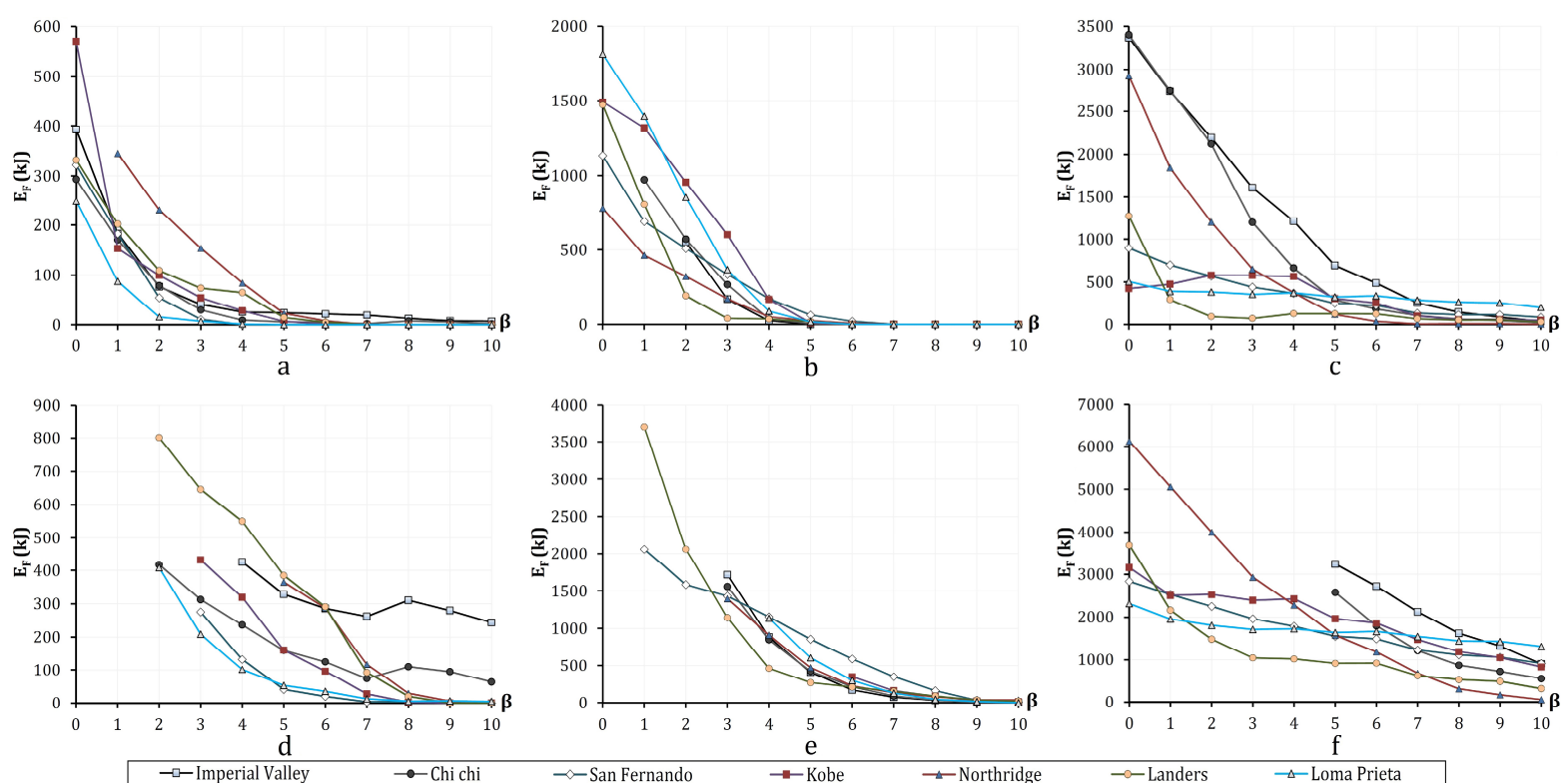

Figure 18
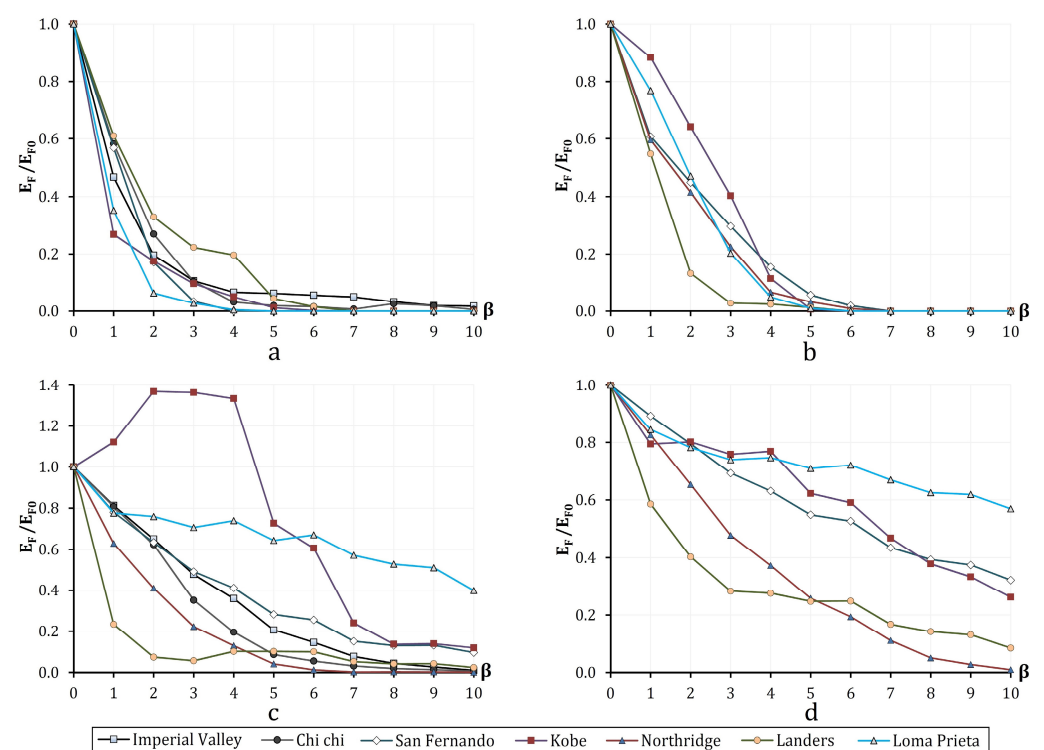

Figure 19
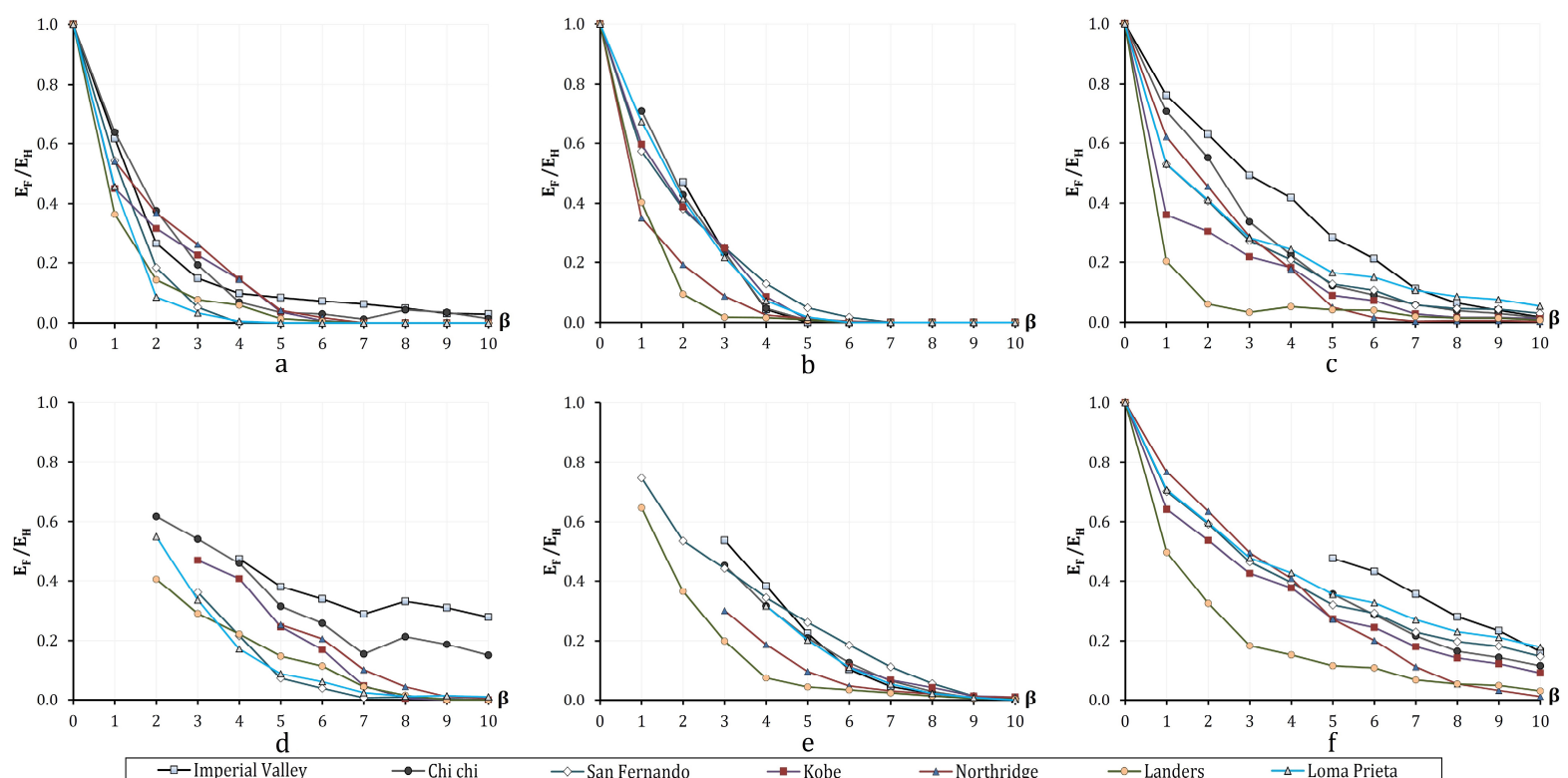

Figure 20 

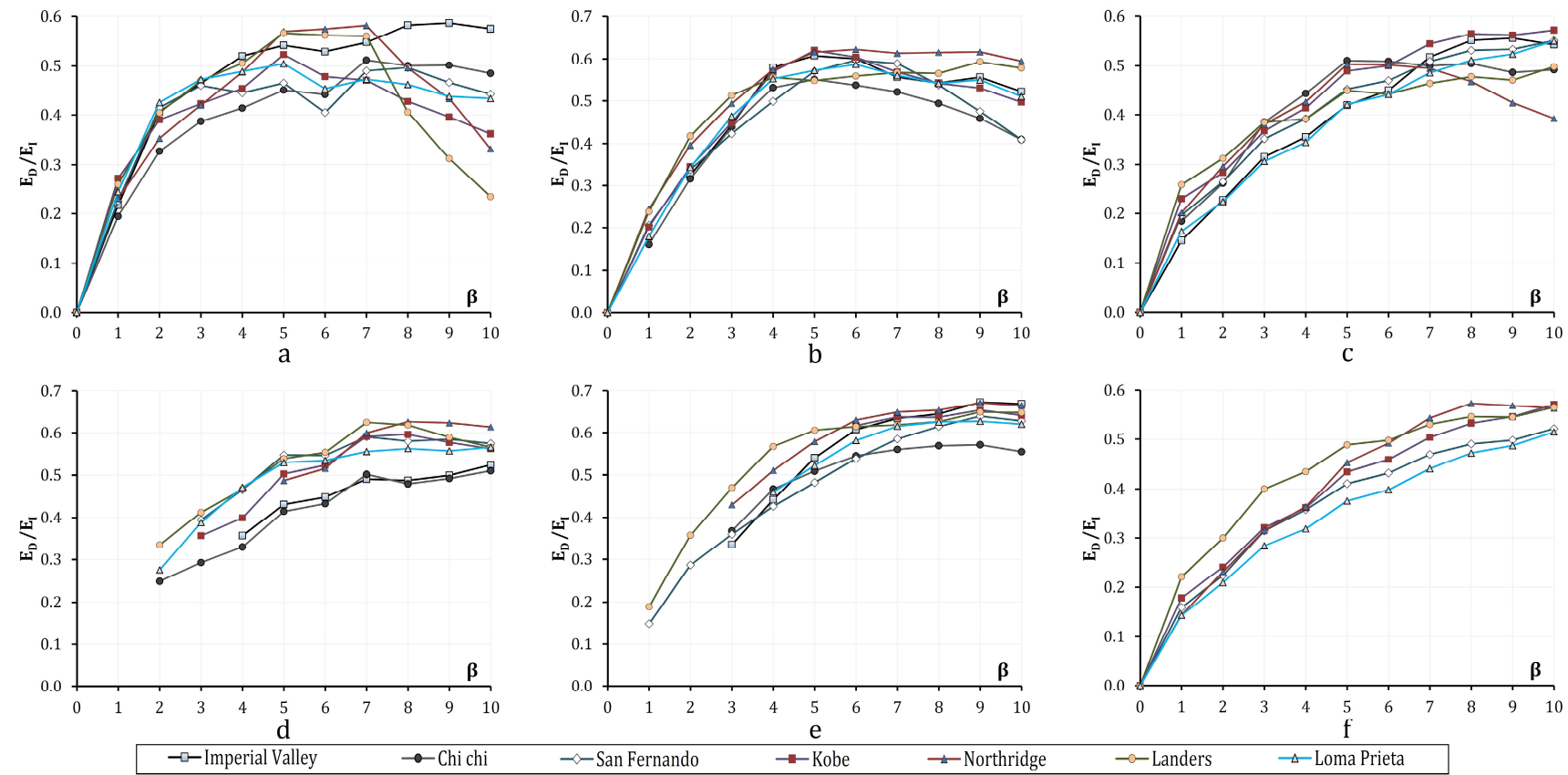

Figure 21
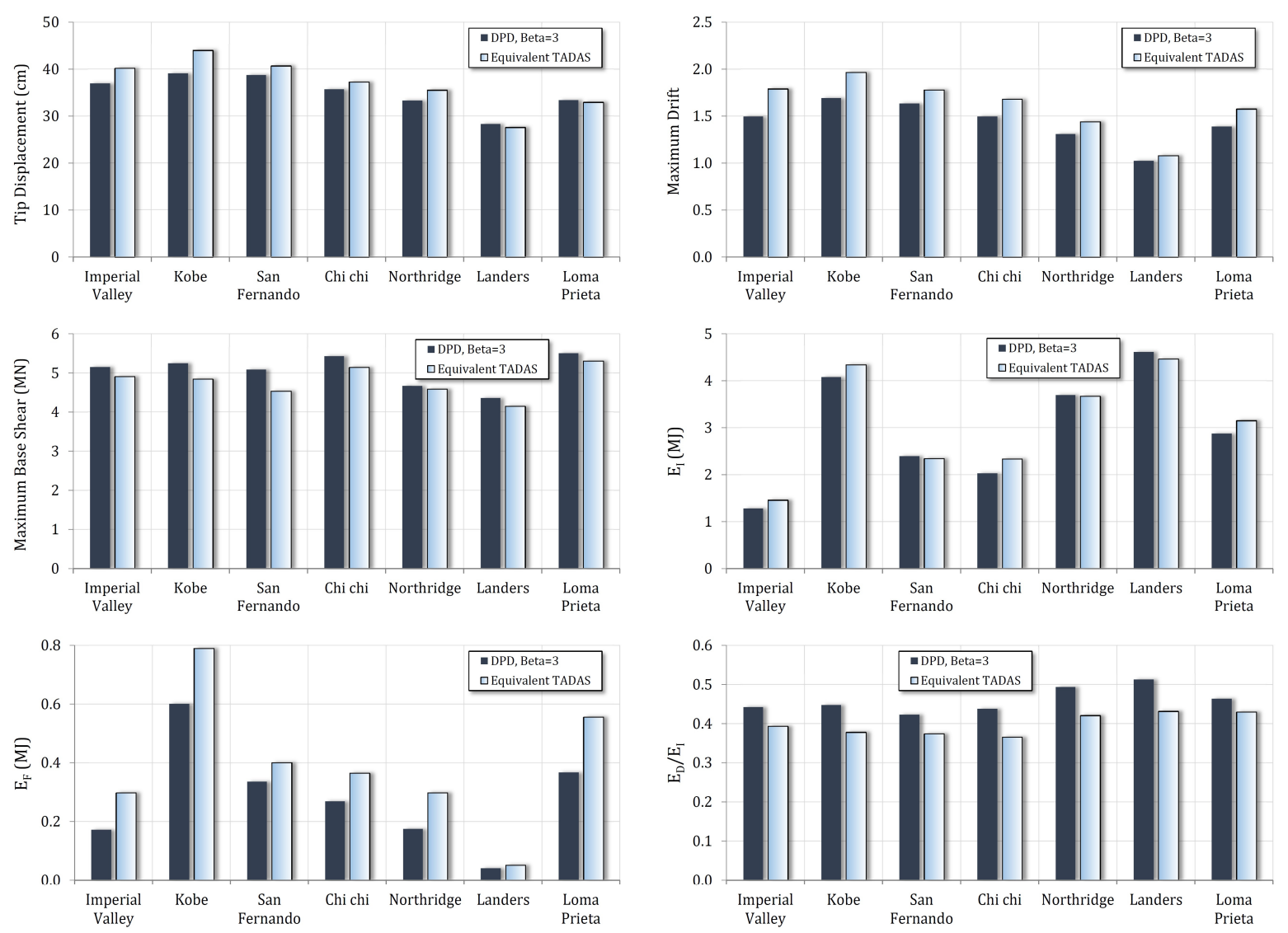

Figure 22 